\title{
Prolonged Seizures Increase Proliferating Neuroblasts in the Adult Rat Subventricular Zone-Olfactory Bulb Pathway
}

\author{
Jack M. Parent, ${ }^{1}$ Vivian V. Valentin, ${ }^{2}$ and Daniel H. Lowenstein ${ }^{3}$ \\ ${ }^{1}$ Department of Neurology, University of Michigan Medical Center, Ann Arbor, Michigan 48104, 2Department of \\ Psychology, University of California, Santa Barbara, Santa Barbara, California 93106, and ${ }^{3}$ Harvard Medical School and \\ Department of Neurology, Beth Israel Deaconess Medical Center, Boston, Massachusetts 02115
}

Neuronal precursors in the adult rodent forebrain subventricular zone (SVZ) proliferate, migrate to the olfactory bulb in a restricted pathway known as the rostral migratory stream (RMS), and differentiate into neurons. The effects of injury on this neurogenic region of the mature brain are poorly understood. To determine whether seizure-induced injury modulates SVZ neurogenesis, we induced status epilepticus (SE) in adult rats by systemic chemoconvulsant administration and examined patterns of neuronal precursor proliferation and migration in the SVZ-olfactory bulb pathway. Within 1-2 weeks after pilocarpine-induced SE, bromodeoxyuridine (BrdU) labeling and Nissl staining increased in the rostral forebrain SVZ. These changes were associated with an increase in cells expressing antigenic markers of SVZ neuroblasts 2-3 weeks after prolonged seizures. At these same time points the
RMS expanded and contained more proliferating cells and immature neurons. BrdU labeling and stereotactic injections of retroviral reporters into the SVZ showed that prolonged seizures also increased neuroblast migration to the olfactory bulb and induced a portion of the neuronal precursors to exit the RMS prematurely. These findings indicate that SE expands the SVZ neuroblast population and alters neuronal precursor migration in the adult rat forebrain. Identification of the mechanisms underlying the response of neural progenitors to seizure-induced injury may help to advance brain regenerative therapies by using either transplanted or endogenous neural precursor cells.

Key words: subventricular zone; olfactory bulb; neurogenesis; pilocarpine; seizures; epilepsy; rostral migratory stream; cell proliferation; neuronal migration; plasticity
The hippocampal dentate gyrus and forebrain subventricular zone (SVZ) generate neurons well into adulthood in the mammalian brain. In all mammalian species that have been studied to date, including humans, dentate granule cells are generated locally by proliferating precursor cells in the subgranular zone of the dentate gyrus (Altman and Das, 1965; Kaplan and Hinds, 1977; Cameron et al., 1993; Kuhn et al., 1996; Eriksson et al., 1998; Gould et al., 1998; Kornack and Rakic, 1999). Similarly, neuronal precursors persist and continue to proliferate in the adult rodent forebrain SVZ (Hinds, 1968; Altman, 1969; Kaplan and Hinds, 1977; Lois and Alvarez-Buylla, 1994; Lois et al., 1996; Thomas et al., 1996). However, unlike in the dentate gyrus, SVZ neuronal progenitors migrate long distances to their final destinations in the olfactory bulb (Kishi, 1987; Luskin, 1993; Lois and Alvarez-Buylla, 1994; Lois et al., 1996; Thomas et al., 1996) (see Fig. $3 H$ ). The immature neurons migrate from the SVZ to the olfactory bulb via a relatively unique form of tangential chain migration (Lois et al., 1996) in a restricted forebrain pathway known as the rostral migratory stream (RMS) (Altman, 1969; Kishi, 1987). The immature neuronal progeny in the SVZ and RMS of adult rodents can be identified by their expression of characteristic markers such as the polysialylated form of neural

\footnotetext{
Received May 23, 2001; revised Jan. 29, 2002; accepted Feb. 1, 2002.

This project was sponsored by National Institutes of Health (NIH) Grant NS02006 to J.M.P. and NIH Grants NS39950 and NS35628 and the March of Dimes Birth Defects Foundation to D.H.L. We thank Susan Hockfield, Virginia Lee, Christopher Walsh, and Genevieve Rougon for providing antibodies and Theo Palmer, Fred Gage, and Richard Mulligan for providing retroviral reagents.

Correspondence should be addressed to Jack M. Parent, Department of Neurology, University of Michigan Medical Center, Neuroscience Laboratory Building, 1103 East Huron Street, Ann Arbor, MI 48104-1687. E-mail: parent@umich.edu. Copyright (C) 2002 Society for Neuroscience 0270-6474/02/223174-15\$15.00/0
}

cell adhesion molecule (PSA-NCAM), neuron-specific $\beta$-tubulin, doublecortin, and collapsin response mediator protein-4 (CRMP-4) (Bonfanti and Theodosis, 1994; Doetsch and AlvarezBuylla, 1996; Thomas et al., 1996; Gleeson et al., 1999; Nacher et al., 2000) (for review, see Peretto et al., 1999). Once the neuroblasts reach the subependymal region of their olfactory bulb target, they disperse radially and differentiate into granule and periglomerular neurons (Luskin, 1993; Lois and Alvarez-Buylla, 1994; Lois et al., 1996; Thomas et al., 1996).

Despite recent advances in understanding this neurogenic pathway, the regulation of neuronal precursor proliferation and migration in the SVZ-olfactory bulb pathway remains poorly understood. In vitro, cells taken from the adult forebrain SVZ can proliferate, self-renew, and give rise to neurons, astrocytes, and oligodendrocytes (Reynolds and Weiss, 1992; Richards et al., 1992; Lois and Alvarez-Buylla, 1993). Proliferation in vitro requires growth factors such as epidermal growth factor (EGF), basic fibroblast growth factor (bFGF), or brain-derived neurotrophic factor (BDNF) (Reynolds and Weiss, 1992; Richards et al., 1992; Lois and Alvarez-Buylla, 1993; Kirschenbaum and Goldman, 1995; Gritti et al., 1996). These molecules also appear to modify SVZ precursor proliferation and cell fate in vivo (Craig et al., 1996; Kuhn et al., 1997; Zigova et al., 1998; Wagner et al., 1999). Several molecules that potentially regulate neuroblast migration to the olfactory bulb include Slit-2 (Hu, 1999; Wu et al., 1999), specific integrin subunits (Jacques et al., 1998), PSANCAM (Tomasiewicz et al., 1993; Cremer et al., 1994; Ono et al., 1994), and BDNF (Zigova et al., 1998). Interestingly, loss of the olfactory bulb target via bulbectomy or RMS transection lesions does not prevent SVZ precursor migration rostrally into the RMS, although the precursors accumulate in the SVZ and prox- 
imal RMS (Jankovski et al., 1998; Alonso et al., 1999; Kirschenbaum et al., 1999). Recent in vitro studies also support a role for glial-derived factors in modulating neuroblast proliferation and migration in the unlesioned SVZ-olfactory bulb pathway (Lim and Alvarez-Buylla, 1999; Mason et al., 2001). The importance of neuroblast interactions with astrocytes is underscored further by the fact that RMS neuroblast chain migration in vivo in the adult rodent occurs within tube-like structures composed of astrocytes (Thomas et al., 1996; Peretto et al., 1997).

Importantly, the presence of ongoing neurogenesis in the mature brain raises the possibility that endogenous precursor cells could be used therapeutically for repair of neuronal loss associated with brain injuries or degenerative disorders (O'Leary, 1993; Lowenstein and Parent, 1999). However, the response of endogenous neural stem or precursor cells to cerebral injury and their potential involvement in neurological disease pathophysiology have received relatively little attention. Recent studies of the adult rodent dentate gyrus reveal that neuronal precursors in this region respond to various forms of injury by increasing neurogenesis (Gould and Tanapat, 1997; Parent et al., 1997; Liu et al., 1998). For example, chemoconvulsant-induced status epilepticus (SE) markedly increases dentate granule cell neurogenesis in the adult rat (Parent et al., 1997; Gray and Sundstrom, 1998). The granule cells that are generated after seizure-induced injury are found in both normal and ectopic locations in the dentate gyrus, and they appear to integrate both normally and aberrantly into existing networks. Several investigations also describe an increase in precursor cell proliferation in the adult rodent forebrain SVZ after various forms of injury. The types of injury include aspiration or transection lesions of the forebrain (Willis et al., 1976; Szele and Chesselet, 1996; Weinstein et al., 1996) and inflammatory demyelination (Calzà et al., 1998). However, the cell fates and ultimate destinations of the neural progenitors that proliferate in response to these forms of injury have not been well characterized. More recent work suggests that SVZ precursors can give rise to glia, either astrocytes or both astrocytes and oligodendrocytes, after brain injury that has been induced by mechanical trauma (Holmin et al., 1997) or chemical demyelination (Nait-Oumesmar et al., 1999).

On the basis of the findings of seizure-induced neurogenesis in the adult rat dentate gyrus and the effects of injury on forebrain SVZ cell proliferation, we sought to determine whether chemoconvulsant-induced SE alters neuroblast proliferation and migration in the SVZ-olfactory bulb pathway of the adult rat. We administered pilocarpine systemically to induce limbic SE, which results in damage to various limbic structures and neocortical areas, including regions near the SVZ-olfactory bulb pathway (Turski et al., 1983). Bromodeoxyuridine (BrdU) and retroviral reporter labeling then was used to identify the cell proliferation and migration patterns of neuroblasts after prolonged seizures. We found that SE in the adult rat expands the neuronal precursor population of the SVZ-olfactory bulb pathway and alters neuroblast migration in the injured forebrain.

\section{MATERIALS AND METHODS}

Seizure induction and cell proliferation assays. Young adult, male Sprague Dawley rats $(180-230 \mathrm{gm})$ were pretreated with injections of atropine methylbromide (5 mg/kg, i.p.; Sigma, St. Louis, MO) and 15 min later were given pilocarpine hydrochloride $(340 \mathrm{mg} / \mathrm{kg}$, i.p.; Sigma) to induce SE. If seizure activity was not initiated within $1 \mathrm{hr}$ after the initial pilocarpine hydrochloride dose, an additional dose of $170 \mathrm{mg} / \mathrm{kg}$ was given. Seizures were monitored behaviorally and then terminated after 2 $\mathrm{hr}$ of SE with diazepam $(10 \mathrm{mg} / \mathrm{kg}$, i.p.; Elkins-Sinn, Cherry Hill, NJ); additional doses of $5 \mathrm{mg} / \mathrm{kg}$ diazepam were given at 45-60 min intervals if convulsive seizure activity persisted. Only rats that displayed $2 \mathrm{hr}$ of continuous convulsive seizure activity (head and forelimb clonus) after pilocarpine treatment were used in these experiments. Control rats were treated identically except that $0.9 \%$ sodium chloride solution was substituted for pilocarpine. Experimental procedures were approved by animal research committees at the University of California, San Francisco and the University of Michigan.

BrdU (Boehringer Mannheim, Indianapolis, IN) was used to label proliferating (S-phase) cells according to two protocols (Miller and Nowakowski, 1988). In the first protocol the rats received two BrdU injections $(50 \mathrm{mg} / \mathrm{kg}$, i.p. in PBS) $1 \mathrm{hr}$ apart on days $1,4,7,14,21$, or 35 after saline or pilocarpine treatment $(n=3-4$ per time point for each group) and were perfused $1 \mathrm{hr}$ after the second BrdU dose. This short survival duration after BrdU was used to assess proliferation in situ, i.e., without allowing sufficient time for the cells to migrate from their location during BrdU incorporation. In the second protocol the same dose of BrdU was administered three times over $6 \mathrm{hr}$ on day 7 after pilocarpine or saline treatment. Animals $(n=6-10$ per time point for each group) were killed 2, 4, 7, or $14 \mathrm{~d}$ after BrdU injections (9, 11, 14, or $21 \mathrm{~d}$ after SE, respectively). In separate experiments the proliferating cells in the rostral SVZ were labeled specifically by injection of replication-incompetent retrovirus carrying nuclear localization signal $\beta$-galactosidase (GPGnlsLZ; a gift of Richard Mulligan, Harvard University, Cambridge, MA) or enhanced green fluorescent protein (LNITGFP; a gift of Theo Palmer and Fred Gage, The Salk Institute, La Jolla, CA) reporters. Vesicular stomatitis virus G (VSV-G) protein pseudotyped retrovirus was generated from $293 \mathrm{GPG}$ producer cells, the supernatant was collected, and the virus was concentrated and titered as described previously (Ory et al., 1996). Animals were anesthetized with intraperitoneal ketamine $(70 \mathrm{mg} / \mathrm{kg})$ and xylazine $(8 \mathrm{mg} / \mathrm{kg})$ and positioned on a stereotactic frame (Kopf Instruments, Tujunga, CA); a $1 \mu \mathrm{l}$ mixture of concentrated $\left(5 \times 10^{8} \mathrm{cfu}\right)$ virus stock, $80 \mu \mathrm{g} / \mathrm{ml}$ Polybrene, and $0.01 \%$ trypan blue was injected stereotactically into the rostral SVZ over 5 min. Injection coordinates relative to bregma were $1.0 \mathrm{~mm}$ posterior and $1.3 \mathrm{~mm}$ lateral, at a depth of $3.3 \mathrm{~mm}$ from the brain surface. The injection sites were identified easily in processed tissue by visualizing the needle track. Adult rats were injected either $2 \mathrm{~d}$ before or $10 \mathrm{~d}$ after pilocarpine or saline treatment ( $n=6-8$ per group), and animals were killed 11, 14, 21, or $35 \mathrm{~d}$ after retrovirus injection. So that the degree of virus diffusion through the SVZ-olfactory bulb pathway could be assessed after focal retrovirus injections, an additional group of three naïve adult rats received identical SVZ injections of GPGnlsLZ retrovirus and were killed $3 \mathrm{~d}$ later.

Tissue processing, Nissl stain, and $\beta$-gal histochemistry. Rats received an overdose of pentobarbital sodium (Abbott Laboratories, North Chicago, IL) and were perfused transcardially with PBS, followed by $2 \%$ paraformaldehyde in $0.1 \mathrm{M}$ sodium acetate, $\mathrm{pH} 6.5(80 \mathrm{ml})$ and then by $2 \%$ paraformaldehyde $/ 0.1 \%$ glutaraldehyde in $0.1 \mathrm{~m}$ sodium borate, $\mathrm{pH} 8.5$ $(360 \mathrm{ml})$. After post-fixation in situ overnight, brains were removed, washed once in PBS, cryoprotected with $30 \%$ sucrose in PBS, and frozen in powdered dry ice. Coronal sections $40 \mu \mathrm{m}$ thick through the rostral SVZ (extending anteriorly from Paxinos and Watson coordinate, bregma $+0.2 \mathrm{~mm}$; Paxinos and Watson, 1998), RMS, and olfactory bulb (see areas $a-c$ in Fig. $3 H$ ) were cut with a cryostat; every sixth or eighth section was processed for Nissl or immunohistochemical stains (see below). Brains from additional animals ( $n=3-4$ per condition) were cut in the sagittal plane (40- $\mu \mathrm{m}$-thick sections), and every sixth section of the medial one-third of each hemisphere was processed for Nissl staining or immunohistochemistry. For Nissl staining the sections were mounted on slides (Superfrost-plus, Fisher Scientific, Pittsburgh, PA), dehydrated and rehydrated in graded ethanols and xylenes, incubated in $1 \%$ cresyl violet for $30 \mathrm{sec}$, decolorized in acetic acid, and then dehydrated and coverslipped with Permount (Fisher Scientific). $\beta$-Gal histochemistry was performed according to established methods (Cepko et al., 1995). $\beta$-Gal expression also was visualized with indirect immunofluorescence histochemistry for double-labeling (see below), and enhanced GFP (eGFP) expression was visualized directly with epifluorescence microscopy.

Immunohistochemistry. Diaminobenzidine peroxidase immunohistochemistry was performed on free-floating tissue sections with the use of antibodies to BrdU or the cell cycle-related kinase cdc2 (p34 ${ }^{\text {cdc2 }}$; Okano et al., 1993) as described previously (Parent et al., 1997). For BrdU immunostaining, DNA first was denatured by incubating tissue sections in $2 \mathrm{~N} \mathrm{HCl}$ for $30 \mathrm{~min}$ at $37^{\circ} \mathrm{C}$, followed by a $10 \mathrm{~min}$ wash in $0.1 \mathrm{~m}$ borate solution, $\mathrm{pH}$ 8.5. Tissue was incubated overnight in primary antibody at 
$4^{\circ} \mathrm{C}$; the primary antibody dilutions that were used included 1:1000 for BrdU (mouse monoclonal; Boehringer Mannheim, Indianapolis, IN) and 1:1000 for cdc2 (mouse monoclonal; Santa Cruz Biotechnology, Santa Cruz, CA). Single and double-label immunofluorescence histochemistry was done according to previously described methods (Parent et al., 1997, 1999). The primary antibody dilutions that were used included 1:100 for BrdU (rat monoclonal; Accurate Chemical, Westbury, NY); 1:1000 for PSA-NCAM (mouse IgM monoclonal; a gift of G. Rougon, Université Aix-Marseille II, France); 1:1000 for doublecortin (rabbit polyclonal; a gift of C. Walsh, Harvard University); 1:200 for GFAP (rat monoclonal; a gift of V. Lee, University of Pennsylvania, Philadelphia, PA) or 1:500 for GFAP (rabbit polyclonal, Sigma); 1:50 for vimentin (mouse monoclonal, Dako, Carpinteria, CA); 1:10,000 for CRMP-4 (also known as TUC-4; rabbit polyclonal; a gift of S. Hockfield, Yale University, New Haven, CT); 1:500 for glucose transporter-1 (Glut-1; rabbit polyclonal; Chemicon, Temecula, CA); 1:1000 for $\beta$-gal (rabbit polyclonal; 5 Prime-3 Prime, Boulder, CO); and 1:400 for class III $\beta$-tubulin (TuJ1 clone, mouse monoclonal; Babco, Berkeley, CA). Secondary antibodies for immunofluorescence were goat anti-rat IgG conjugated to fluorescein isothiocyanate (FITC) or Texas Red, goat anti-mouse IgG conjugated to FITC or Texas Red, goat anti-rabbit IgG conjugated to FITC or Texas Red, and goat anti-mouse IgM conjugated to Texas Red (all species cross-adsorbed and obtained from Jackson ImmunoResearch Laboratories, West Grove, PA) at 1:400 dilutions. Tissue was incubated in secondary antibody overnight at $4^{\circ} \mathrm{C}$. For double-label immunofluorescence with rat anti-BrdU and a second primary antibody, free-floating sections were incubated in the second primary antibody for $24 \mathrm{hr}$ at $4^{\circ} \mathrm{C}$, washed with Tris-buffered saline (TBS; $0.15 \mathrm{M} \mathrm{NaCl}, 0.1 \mathrm{M}$ Tris-HCl, $\mathrm{pH}$ 7.6) for $45 \mathrm{~min}$, post-fixed in $4 \%$ PFA for $20 \mathrm{~min}$, rinsed three times with TBS, and denatured with $2 \mathrm{~N} \mathrm{HCl}$ as described above. After three TBS washes and a $1 \mathrm{hr}$ incubation in blocking solution [ $10 \%$ normal goat serum, $0.4 \%$ Triton X-100, 3\% (w/v) bovine serum albumin, and $1 \%(\mathrm{w} / \mathrm{v})$ glycine in TBS] the sections were incubated in rat anti-BrdU antibody and the second primary antibody for another $24 \mathrm{hr}$ at $4^{\circ} \mathrm{C}$. Immunofluorescence images were obtained by using a Bio-Rad MRC 1024 confocal laser microscope (Hercules, CA) as single optical images or $z$-series stacks, visualized with NIH Image version 1.61 software (Bethesda, MD), and transferred to Adobe Photoshop for color merging (Adobe Systems, Mountain View, CA).

Quantification and statistical analyses. Nissl staining and BrdU immunostaining within or adjacent to the RMS were quantified in images from every sixth coronal section through the mid-RMS (between Paxinos and Watson coordinates, bregma +3.0 and $+4.5 \mathrm{~mm}$ ) or midportion of the olfactory bulb captured at $200 \times$ magnification and digitized with a Spot 2 digital camera (Diagnostic Instruments, Sterling Heights, MI). For PSA-NCAM immunostaining, images from the same RMS regions were obtained at $200 \times$ magnification with a Bio-Rad MRC 1024 confocal laser microscope. Then all images were imported into N IH Image version 1.61 software for blinded densitometric analysis of BrdU, PSA-NCAM, and Nissl staining. The region of interest (RMS in cross section or rectangular areas centered over the subependymal or granule cell layer for the olfactory bulb) was selected manually with a wand and drawing tablet, and measurements were made from one hemisphere by using six sections per animal from three to six animals per group. For BrdU immunostaining in the RMS or olfactory bulb the mean area that was immunostained per section was determined for each animal; then group means and SEM for each time point were calculated. BrdU immunostaining adjacent to the RMS was calculated by drawing a square region of interest centered over the RMS, subtracting out the RMS, and determining the area immunostained in the remainder of the square. For Nissl staining and PSA-NCAM immunohistochemistry the cumulative RMS area that was labeled was determined for each animal, and group means and SD values were calculated. Statistical comparisons between groups were made by using two-tailed Student's $t$ test with StatView software (Abacus Concepts, Berkeley, CA).

\section{RESULTS}

\section{Pilocarpine-induced SE increases proliferating cell numbers in the rostral SVZ}

We first examined the effect of prolonged seizures on cell proliferation in the adult rat forebrain SVZ. The distribution of mitotically active cells at different times after pilocarpine-induced SE was assessed by BrdU labeling and detection of the endogenous cell cycle marker cdc2 (Okano et al., 1993). BrdU was given as two pulses, 1 and $2 \mathrm{hr}$ before perfusion, to label S-phase cells in situ at multiple time points after seizure induction (see Materials and Methods). Compared with controls, SVZ BrdU immunoreactivity (IR) was increased markedly $7 \mathrm{~d}$ after pilocarpine treatment (Fig. $1 A-D$ ) at rostral levels of the SVZ (between Paxinos and Watson coordinates, bregma +1.6 and $+2.5 \mathrm{~mm}$; labeled $a$ in Fig. $3 H$ ). In some animals BrdU labeling at this SVZ level was increased to a lesser extent at 4 and $14 \mathrm{~d}$ after SE (Fig. $1 B, D$ ), but the magnitude was variable and the increase was not present in all animals. No changes in rostral SVZ BrdU labeling occurred at 1 , 21 , or $35 \mathrm{~d}$ after seizure induction or at any time point at more posterior levels of the SVZ when compared with controls (between Paxinos and Watson coordinates, bregma +0.2 and +1.6 $\mathrm{mm}$; data not shown). To confirm the distribution of proliferating cells obtained with BrdU labeling after SE, we analyzed the pattern of immunostaining for the cell cycle antigen cdc2, a molecule known to be expressed in mitotically active cells in the adult rodent brain (Okano et al., 1993). cdc2 expression in the rostral SVZ also was increased at $7 \mathrm{~d}$ after SE (Fig. 1E,F), and the pattern was nearly identical to that of BrdU labeling (Fig. $1 A, C)$. The distribution of cdc2-expressing cells at other time points after seizures and in controls also correlated strongly with that of BrdU-labeled cells. The majority of the proliferating cells identified by BrdU or cdc2 immunocytochemistry was located in the dorsal or dorsolateral aspect of the SVZ in both control and pilocarpine-treated rats (Fig. 1). This location is consistent with previous studies of cell proliferation in the adult rodent SVZ (Okano et al., 1993; Peretto et al., 1999).

In addition to enhanced cell proliferation, we observed an enlargement of the dorsolateral portion of the SVZ after SE. Nissl staining revealed that the maximal expansion of the rostral SVZ in pilocarpine-treated rats occurred $14 \mathrm{~d}$ after SE in the same SVZ regions as the increase in proliferating cells (Fig. $1 G, H)$. The seizure-induced increase in SVZ Nissl staining first appeared within $7 \mathrm{~d}$ and persisted for at least 3 weeks after seizures. Nissl staining of the SVZ from rats $35 \mathrm{~d}$ after pilocarpine treatment appeared similar to that in controls (data not shown). No difference in the SVZ cell-packing density between controls and pilocarpine-treated rats was observed. Although some temporal overlap of seizure-induced cell proliferation and increased cellularity was seen, the maximal increase in SVZ mitotic activity after pilocarpine-induced SE preceded the peak increase in SVZ Nissl staining. Therefore, the temporal and spatial patterns are consistent with the idea that the enlargement of the rostral SVZ resulted from the accumulation of proliferating cells after SE.

\section{SE expands the rostral forebrain SVZ neuroblast population}

We next sought to determine whether the seizure-induced SVZ expansion corresponded to an increase in the number of immature neurons. The SVZ neuroblasts are known to express a variety of immature neuronal markers even before they enter the migratory pathway (for review, see Peretto et al., 1999). We first examined the expression pattern of PSA-NCAM, a molecule necessary for neuroblast migration to the olfactory bulb (Tomasiewicz et al., 1993; Cremer et al., 1994; Ono et al., 1994), at various times after pilocarpine treatment. SE markedly increased immunoreactivity for PSA-NCAM in the rostral SVZ within $14 \mathrm{~d}$ after pilocarpine treatment compared with controls (Fig. 2A,B). The PSA-NCAM-IR cells were both more numerous 

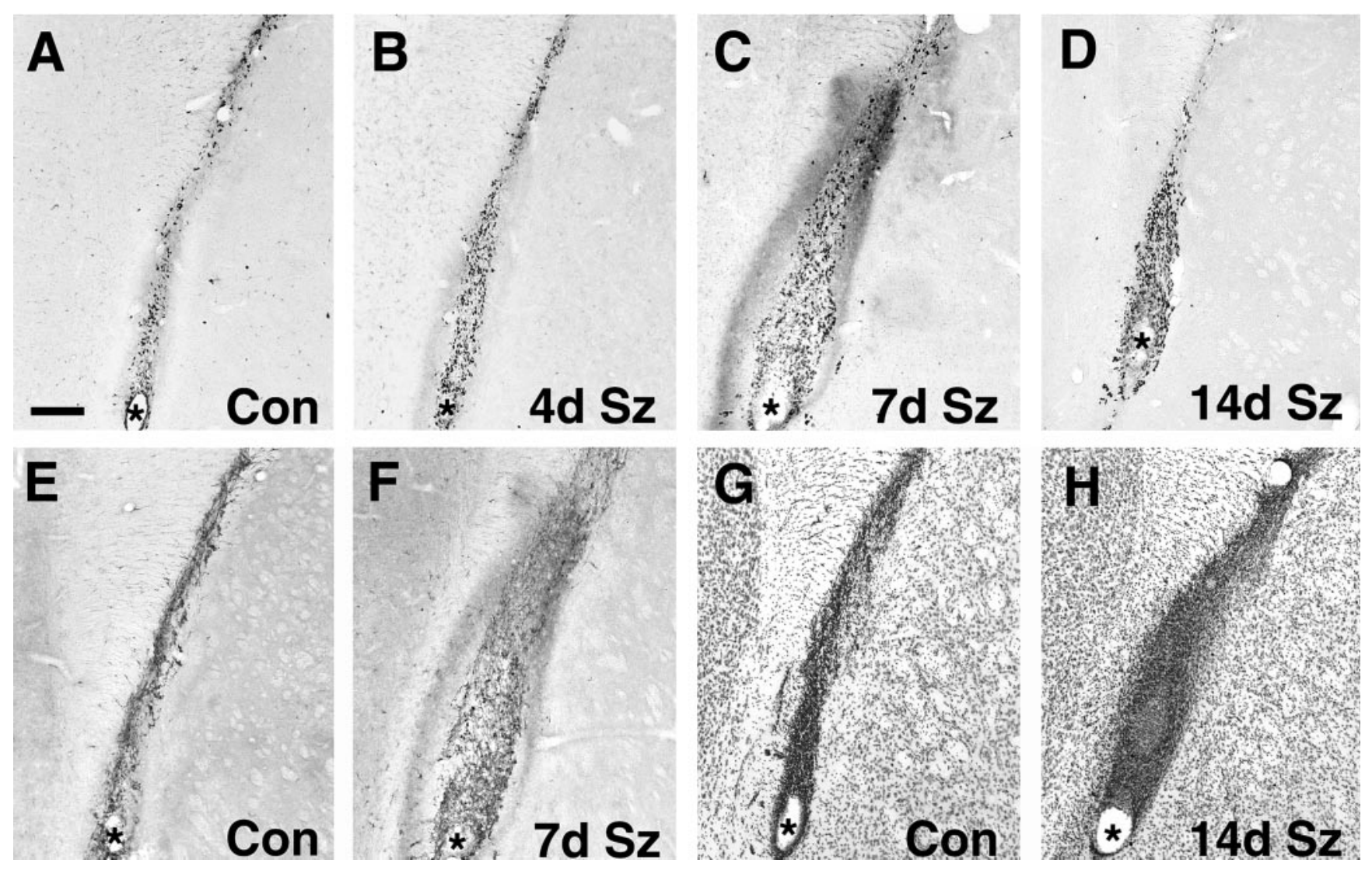

Figure 1. Increased cell proliferation and expansion of the adult rat rostral SVZ after pilocarpine-induced status epilepticus (SE). $A-D$, Coronal sections through the rostral forebrain SVZ immunostained for BrdU after pulse labeling. Compared with the baseline level of mitotic activity in a representative control rat $(A)$, the degree of cell proliferation is increased markedly $7 \mathrm{~d}$ after pilocarpine treatment $(C)$ and elevated more modestly at $4 \mathrm{~d}(B)$ and $14 \mathrm{~d}(D)$ after seizures. $E, F$, cdc2 immunostaining shows a similar pattern of increased SVZ cell proliferation $7 \mathrm{~d}$ after SE $(F)$ compared with a control animal $(E) . G, H$, Coronal Nissl-stained sections through the rostral SVZ show that the SVZ is expanded greatly in a pilocarpine-treated rat $14 \mathrm{~d}$ after SE $(H)$ compared with a typical control animal $(G)$. Sections in $A-H$ correspond approximately to level $a$ in Figure $3 H$. The $a s t e r i s k$ in each panel denotes the lateral ventricle. Scale bars: $A-H$ (in $A), 100 \mu \mathrm{m}$. Con, Control; $S z$, after seizure.

and more intensely labeled in the pilocarpine-treated animals, although the cellular morphology was similar between the two groups. The increase in SVZ PSA-NCAM expression peaked at 14-21 d after seizures, and the effect declined by $35 \mathrm{~d}$ after pilocarpine treatment. Because PSA-NCAM expression is not entirely specific for neurons (Ben-Hur et al., 1998; Theodosis et al., 1999), we also performed immunostaining for additional markers normally expressed by neuroblasts in the SVZ. Pilocarpine-treated animals showed increased expression of neuron-specific class III $\beta$-tubulin (Fig. $2 C, D$ ), doublecortin (Fig. $2 E, F$ ), and CRMP-4 (data not shown) 2-3 weeks after SE. The seizure-induced increase in rostral SVZ neuronal precursors occurred in the same dorsolateral location as that of enhanced cell proliferation and also extended to more caudal levels of the SVZ compared with the increase in BrdU labeling (for example, see Fig. 2F). As expected, the rise in mitotic activity preceded the expansion of SVZ neuroblasts in pilocarpine-treated rats. Therefore, newly generated cells accumulated in the SVZ and expressed markers consistent with a neuronal phenotype.

At the light microscopic level the SVZ and RMS cells expressing PSA-NCAM and other immature neuronal markers had the typical morphology of neuronal precursors arranged in tightly packed clusters or chains (see Fig. $4 L$; data not shown). In the normal adult rodent SVZ, neuroblasts are associated intimately with surrounding astrocytes that eventually form tube-like struc- tures through which the neuroblasts migrate within the RMS (Gates et al., 1995; Doetsch and Alvarez-Buylla, 1996; Thomas et al., 1996; Peretto et al., 1997). To determine whether the seizureinduced increase in SVZ cellularity also involved increases in the astroglial component, we immunostained for GFAP and vimentin, markers known to be expressed by SVZ astrocytes (Gates et al., 1995; Peretto et al., 1999). Pilocarpine-induced SE did not increase SVZ GFAP- or vimentin-IR, and no changes in the structural arrangement of glia in the SVZ were noted (Fig. $2 G, H$; data not shown). This contrasted with the marked increase in GFAP- and vimentin-IR that was found adjacent to the SVZ (Fig. $2 \mathrm{H}$ ) and in other regions of expected seizure-induced injury (see Fig. $4 H, K)$. Taken together, these findings indicate that SE causes a relatively specific expansion of the proliferating neuroblast population in the adult rat rostral SVZ.

\section{The numbers of RMS neuroblasts increase after SE}

The RMS is a cell-dense region that extends through the medial forebrain from the rostral portion of the SVZ anteriorly to the olfactory bulb (Fig. 3H). It contains neuronal precursors that arise from the forebrain SVZ and migrate to the olfactory bulb (Luskin, 1993; Lois and Alvarez-Buylla, 1994; Lois et al., 1996; Peretto et al., 1999). On the basis of our finding of increased numbers of dividing neuroblasts in the rostral SVZ after SE, we also expected to see more newly generated cells migrating within 

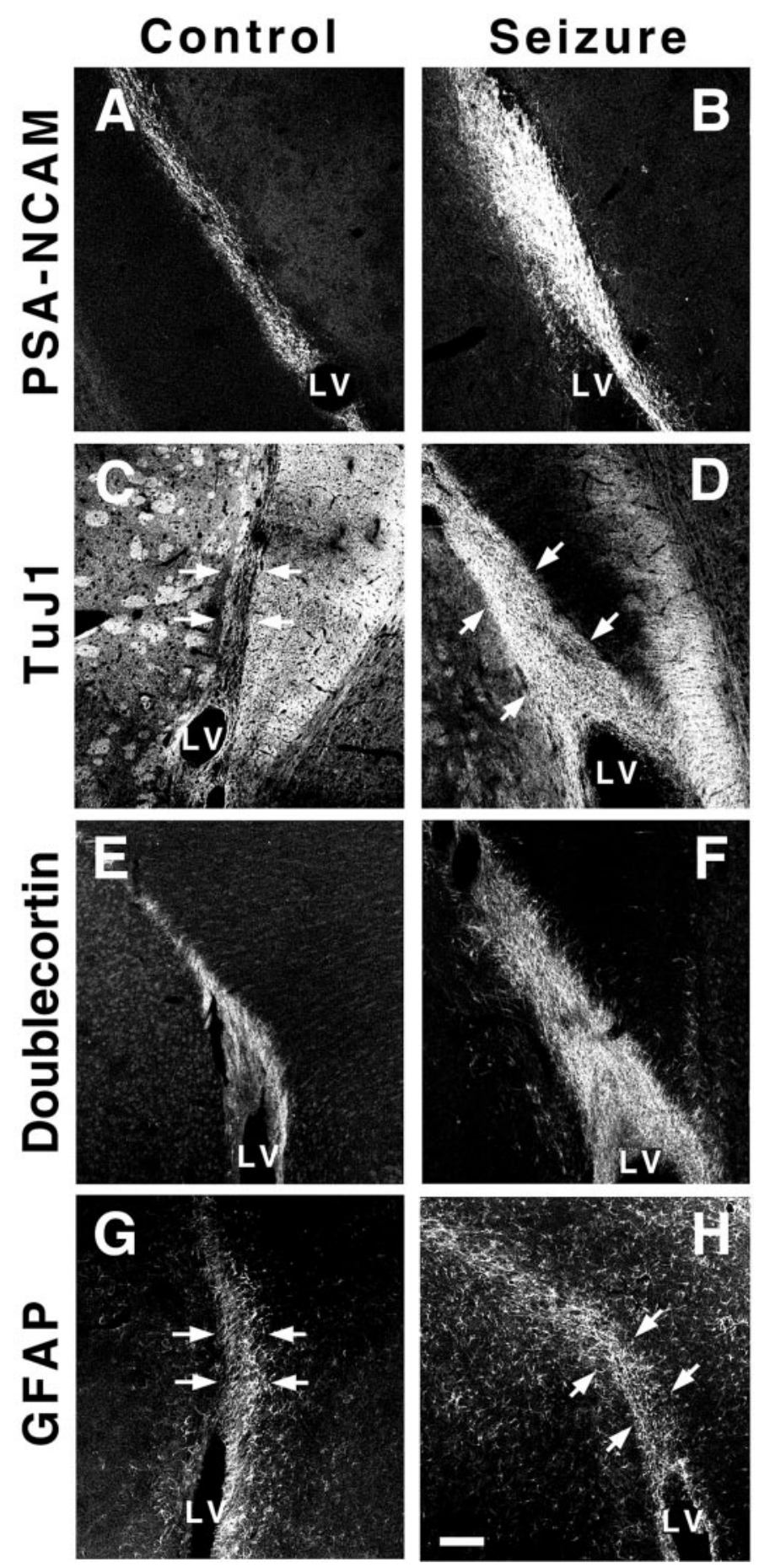

Figure 2. Prolonged seizures increase neuroblast numbers in the forebrain SVZ. $A-F$, Confocal images of coronal sections stained by indirect immunofluorescence with the use of antibodies that recognize immature neurons in the rostral SVZ of adult rats 2 weeks after saline $(A, C, E)$ or pilocarpine $(B, D, F)$ treatment. Both the amount and intensity of immunostaining are increased after SE. Note that the neuron-specific class III $\beta$-tubulin (TuJ1) antibody also labels differentiated neurons outside the SVZ $(C, D)$, whereas immunostaining for PSA-NCAM $(A, B)$ and doublecortin $(E, F)$ is restricted mainly to the SVZ. $G, H$, Immunofluorescence staining for the astrocyte protein GFAP in the rostral SVZ of an adult rat 2 weeks after pilocarpine treatment $(H)$ is similar to the control $(G)$, although GFAP-IR is increased outside the SVZ region $(H)$. Arrows in $C, D, G$, and $H$ outline the dorsolateral SVZ. Scale bar (in $H$ ), $100 \mu \mathrm{m}$. $L V$, Lateral ventricle; PSA-NCAM, polysialylated neural cell adhesion molecule; GFAP, glial fibrillary acidic protein. the RMS. Nissl staining of the RMS at different time points after seizures revealed that this pathway markedly increased in size within $11 \mathrm{~d}$ after pilocarpine treatment. The increase was maximal after $\sim 14 \mathrm{~d}$ (Fig. $3 A, B$ ) and appeared qualitatively throughout the entire length of the RMS. We quantified the area of Nissl staining in the midportion of the RMS (Fig. $3 H$, region labeled $b$ ) in control and pilocarpine-treated rats. The cross-sectional area of the RMS of pilocarpine-treated rats was significantly greater than it was of controls at 14 and $21 \mathrm{~d}$ after seizures (Fig. $3 G$ ).

To determine whether the RMS expansion was attributable to increased numbers of newly generated cells migrating in this pathway after seizures, we used BrdU to label S-phase cells and determined their locations after several different survival periods. The $7 \mathrm{~d}$ after-pilocarpine time point was chosen to administer BrdU because this was the time of maximal BrdU labeling in the rostral SVZ after SE (Fig. 1). When animals were killed within 1 hr of the last BrdU injection on day 7, we observed a qualitative increase in BrdU-IR. Quantification of BrdU labeling in the midportion of the RMS at this time point after SE showed a trend toward an increase in the area immunostained in pilocarpinetreated animals that was not statistically significant $(p=0.08$, two-tailed $t$ test). At 1 week after BrdU incorporation (2 weeks after SE) a marked increase in the number of BrdU-IR cells was found throughout the entire RMS compared with controls (Fig. $3 C-F)$. The majority of the BrdU-labeled nuclei had a fusiform appearance on parasagittal sections characteristic of migrating cells. Quantification of coronal sections through the midportion of the RMS at 2 weeks after SE revealed significantly more BrdU-IR cells in pilocarpine-treated animals $(p=0.01$, twotailed $t$ test). Minimal numbers of BrdU-IR cells were seen in the RMS of pilocarpine- or saline-treated rats after 3 weeks ( 2 weeks after BrdU administration), indicating that most of the proliferating cells had migrated to the olfactory bulb or failed to survive. cdc2-IR also increased in the RMS of pilocarpine-treated animals compared with controls (data not shown). The cdc2 expression in migrating neuroblasts and BrdU incorporation of RMS cells within 2 hr after BrdU administration (see Fig. 7) are consistent with existing evidence that these cells remain mitotically active as they migrate (Kishi, 1987; Luskin, 1998).

On the basis of our finding of a seizure-induced increase in SVZ neuroblasts and an expansion of proliferating cells in the RMS, we expected SE to increase the numbers of migrating neuroblasts similarly within the RMS. Corresponding to the greater cellularity, the population of PSA-NCAM-IR neuroblasts also expanded after SE (Fig. 4A,B). Measurement of PSANCAM immunostaining in the RMS at various time points after pilocarpine treatment revealed a significant increase on day 14 after SE (Fig. 3G). In addition to PSA-NCAM-IR, prolonged seizure activity also increased immunostaining for doublecortin, neuron-specific $\beta$-tubulin, and CRMP-4 in the RMS (Fig. $4 D, E$; data not shown). To examine astroglial lineage cells, we immunostained sections from pilocarpine- or saline-treated rats with antibodies to GFAP or vimentin. Although the pattern of GFAPand vimentin-IR in the innermost region of the migratory pathway appeared to maintain the typical tubular architecture, immunostaining increased markedly adjacent to and well outside the RMS in pilocarpine-treated rats (Fig. 4G,H,J,K; data not shown). No cellular colocalization was present on confocal microscopic analysis when double-label immunofluorescence for PSA-NCAM or doublecortin and these astrocytic markers was performed (data not shown). To confirm that the labeled RMS cells were newly generated, we performed immunofluorescence double labeling 


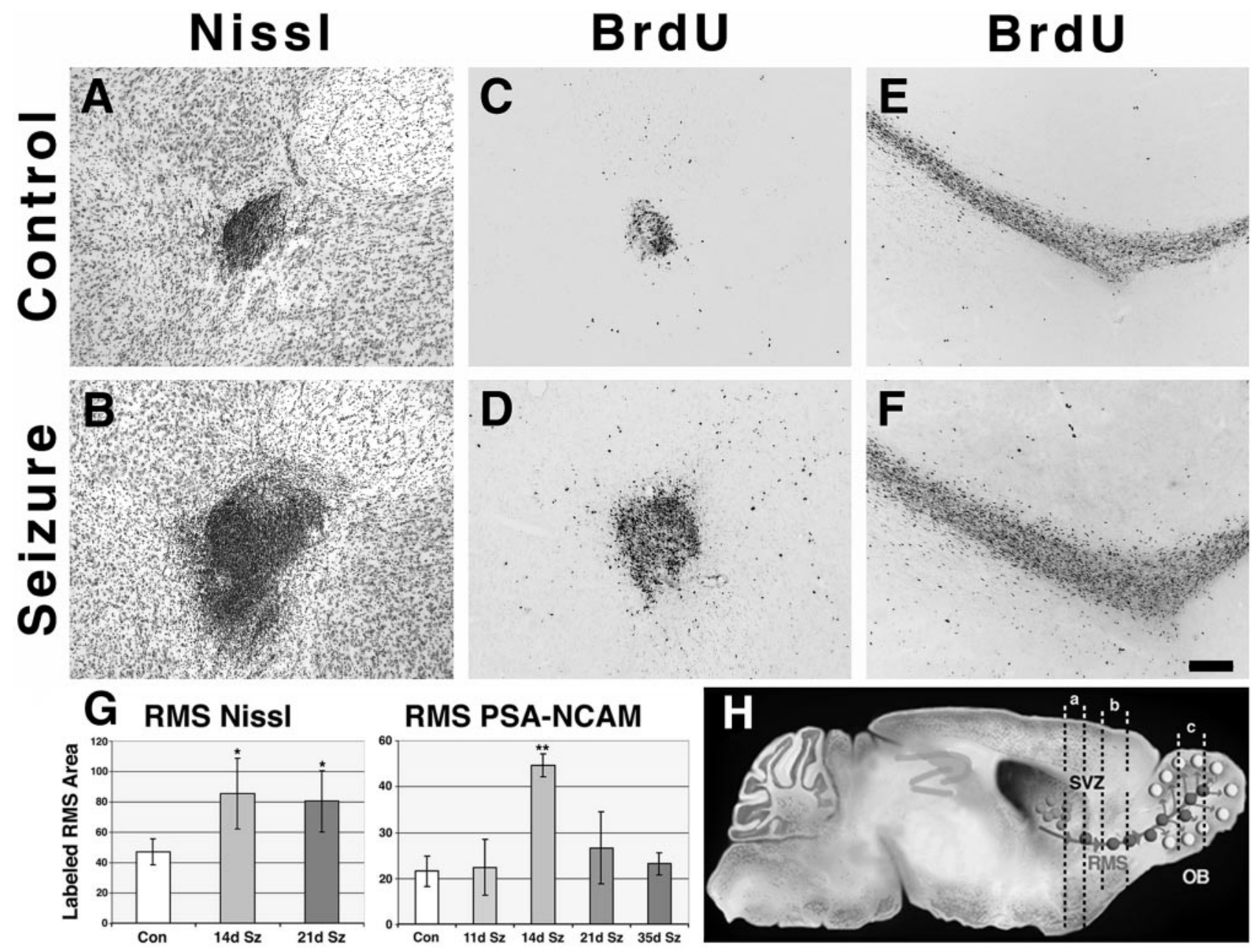

Figure 3. Status epilepticus expands the RMS. $A, B$, Nissl staining of coronal sections (corresponding approximately to level $b$ in $H$ ) shows a marked enlargement of the RMS 2 weeks after pilocarpine treatment $(B)$ compared with a control $(A)$. $C-F$, BrdU immunostaining of coronal $(C, D)$ and parasagittal $(E, F)$ sections from adult rats 2 weeks after pilocarpine $(D, F)$ or saline $(C, E)$ treatment and 1 week after BrdU administration. The number of mitotically active cells in the RMS is increased markedly after seizures $(D, F)$. The parasagittal sections $(E, F$; olfactory bulb out of view to the right $)$ demonstrate increased BrdU labeling throughout nearly the entire length of RMS. Note also that many more BrdU-IR cells are scattered outside the RMS of the pilocarpine-treated rats $(D, F)$. G, Quantification of RMS area identified by Nissl staining (left; see Materials and Methods) shows significant cellular expansion of the RMS at 2 and 3 weeks after SE. The area of PSA-NCAM immunoreactivity in the RMS (right) also is increased significantly above control levels at 2 weeks after SE. ${ }^{*} p<0.05 ;{ }^{* *} p<0.01$. Error bars represent SD. $H$, Schematic parasagittal view of the adult rodent brain showing the tangential migratory route of neuronal precursors from the rostral SVZ to the olfactory bulb. Dashed pairs of vertical lines labeled $a, b$, and $c$ denote approximate regions from which coronal sections are shown in the figures (see Results and legends). Scale bar (in $F$ ), $100 \mu \mathrm{m}$. $S z$, After seizure; $O B$, olfactory bulb.

for BrdU and immature neuronal markers. In rats given BrdU injections $7 \mathrm{~d}$ after pilocarpine treatment and killed 1 week later, many of the BrdU-labeled cells in the RMS coexpressed neuronspecific $\beta$-tubulin or PSA-NCAM (see Fig. 6A,B). The RMS BrdU-IR cells also coexpressed CRMP-4 after SE (see Fig. 8A), but not GFAP or the endothelial marker GLUT-1 (data not shown). Like controls, cells expressing immature neuronal markers in the RMS of pilocarpine-treated animals exhibited morphological features consistent with migrating neuroblasts (Fig. 4L).

\section{More neuronal precursors migrate to the olfactory bulb after SE}

Previous reports have shown that the SVZ and RMS expand after either removal of the olfactory bulb target (Kirschenbaum et al., 1999) or lesioning of the migratory pathway (Jankovski et al., 1998; Alonso et al., 1999). This raises the possibility that the SE-induced expansion of neuronal precursors in the RMS that we observed might result from their failure to migrate to the olfactory bulb (a "logjam" effect) rather than from an overall increase in SVZ neuroblast production or survival. To determine whether SVZ neuroblasts continue to migrate to the olfactory bulb after seizure-induced injury, we labeled proliferating cells with BrdU $7 \mathrm{~d}$ after SE and determined the pattern of BrdU labeling in the olfactory bulb after progressively longer survival durations. When BrdU was administered $7 \mathrm{~d}$ after pilocarpine or saline treatment and the animals were killed $1 \mathrm{hr}$ later, only rare labeled cells were found in the olfactory bulb of rats in either group (Fig. $5 A, B)$. When animals survived for $2 \mathrm{~d}$ additionally, however, BrdU-IR cells began to appear in the olfactory bulb subependymal region, and significantly more labeled cells were found in pilocarpine-treated rats than in controls (Fig. 5C,D,G). By $7 \mathrm{~d}$ after BrdU administration (14 d after treatment) many more labeled cells had reached the olfactory bulb granule cell and 


\section{Control}
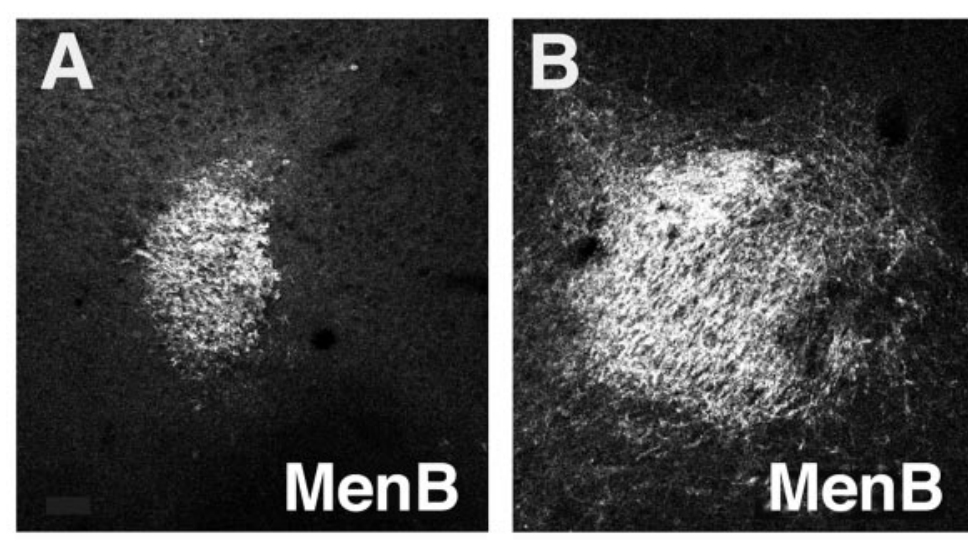

\section{4d Seizure}
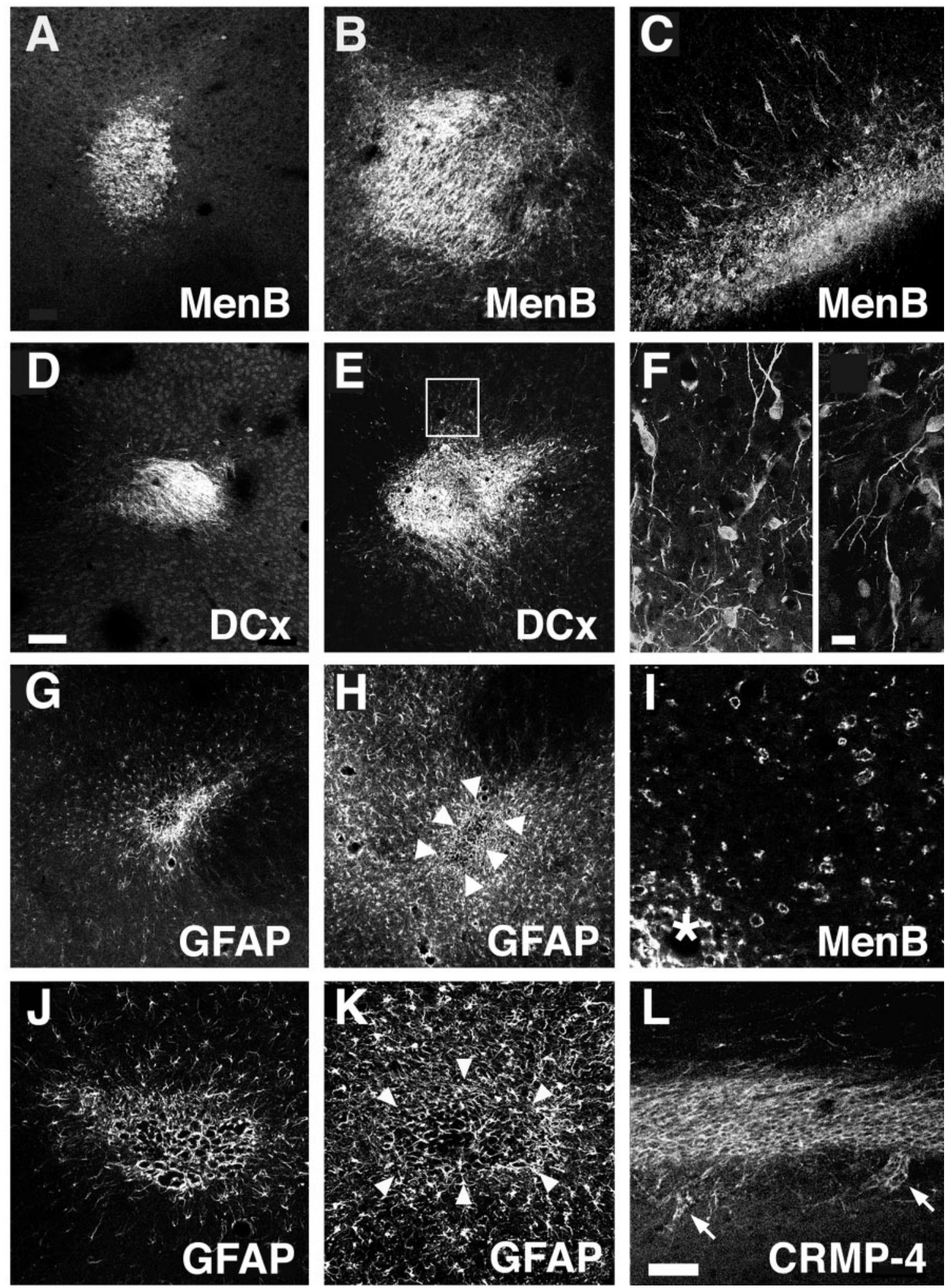

Figure 4. Immunostaining to detect immature neurons and glia in the adult rat RMS after SE. Shown are confocal images of coronal sections through the RMS immunostained for PSA-NCAM $(M e n B ; A-C, I)$, doublecortin $(D C x ; D-F)$, or GFAP $(G, H, J, K)$. Sections from controls are shown in the left panels and from pilocarpine-treated rats in the middle and right panels. $A-C, I$, PSA-NCAM-IR in the RMS increased markedly 2 weeks after SE ( $B$ ) compared with the saline-treated control $(A)$, and many labeled cells are seen extending from the borders of the RMS at both proximal $(B, I)$ and distal $(C)$ RMS levels that are not seen in the control $(A)$. The asterisk in $I$ denotes the edge of the RMS. $D-F$, Doublecortin-IR in the RMS (at slightly more distal levels compared with $A, B$ ) also is increased by SE. $F$ shows two optical images at different levels of a higher magnification (Figure legend continues.) 


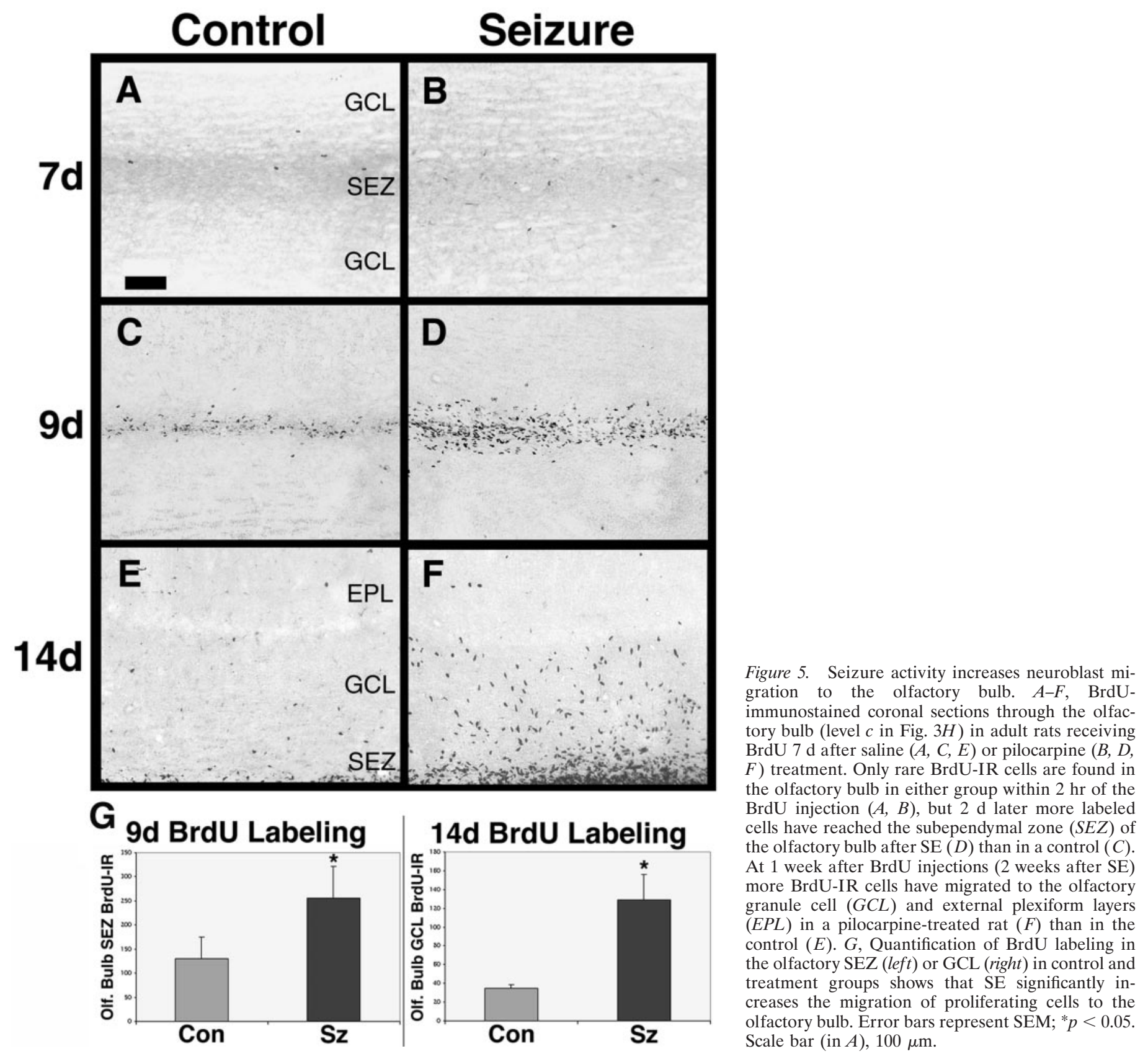

external plexiform layers after SE than in controls (Fig. $5 E-G$ ). Two weeks after BrdU administration (21 d after SE) immunoreactive cells were present in both the granule and periglomerular layers of the olfactory bulb, and the pattern of BrdU labeling was indistinguishable between pilocarpine- and saline-treated rats (data not shown). These findings suggested that not only were SVZ precursors able to migrate to the olfactory bulb after SE but that they did so in greater numbers than in controls. Increased cell death of olfactory bulb neuroblasts or dilution of nuclear BrdU content below levels of immunocytochemical detection after SE is likely to explain the absence of increased labeling at $21 \mathrm{~d}$ in the pilocarpine-treated rats. As expected, BrdU-labeled cells in the olfactory bulb examined between 9 and $21 \mathrm{~d}$ after SE expressed neuronal markers (Fig. 6C,D; data not shown).

To confirm that the newborn neurons in the olfactory bulb migrated from the SVZ after SE, we stereotactically injected

(Figure legend continued.) $z$-series through the boxed region in E. Note that the doublecortin-IR cells extending out from the RMS have the morphology of migrating neuroblasts. $G, H, J, K$, GFAP immunostaining of coronal sections through the RMS $14 \mathrm{~d}$ after saline $(G, J)$ or pilocarpine $(H, K)$ treatment. The astrocytic elements within the central portion of the RMS maintain a similar tubular architecture 2 weeks after SE (enclosed by white arrowheads in $H, K$ ), but the outer portion of the RMS is indistinct when compared with controls, and substantial astroglial proliferation is present outside the RMS after seizures. $L$, Sagittal section of CRMP-4-IR, migrating neuroblasts in the RMS 2 weeks after SE. Note the chain-like structures of labeled cells extending inferiorly from the RMS (white arrows), which were not present in controls (data not shown). Scale bars: $A, B, D, E, G, H$ (in $D$ ), $75 \mu$ m; $C$, $J-L$ (in $L$ ), $50 \mu \mathrm{m} ; F, I$ (in $F$ ), $10 \mu \mathrm{m}$. 

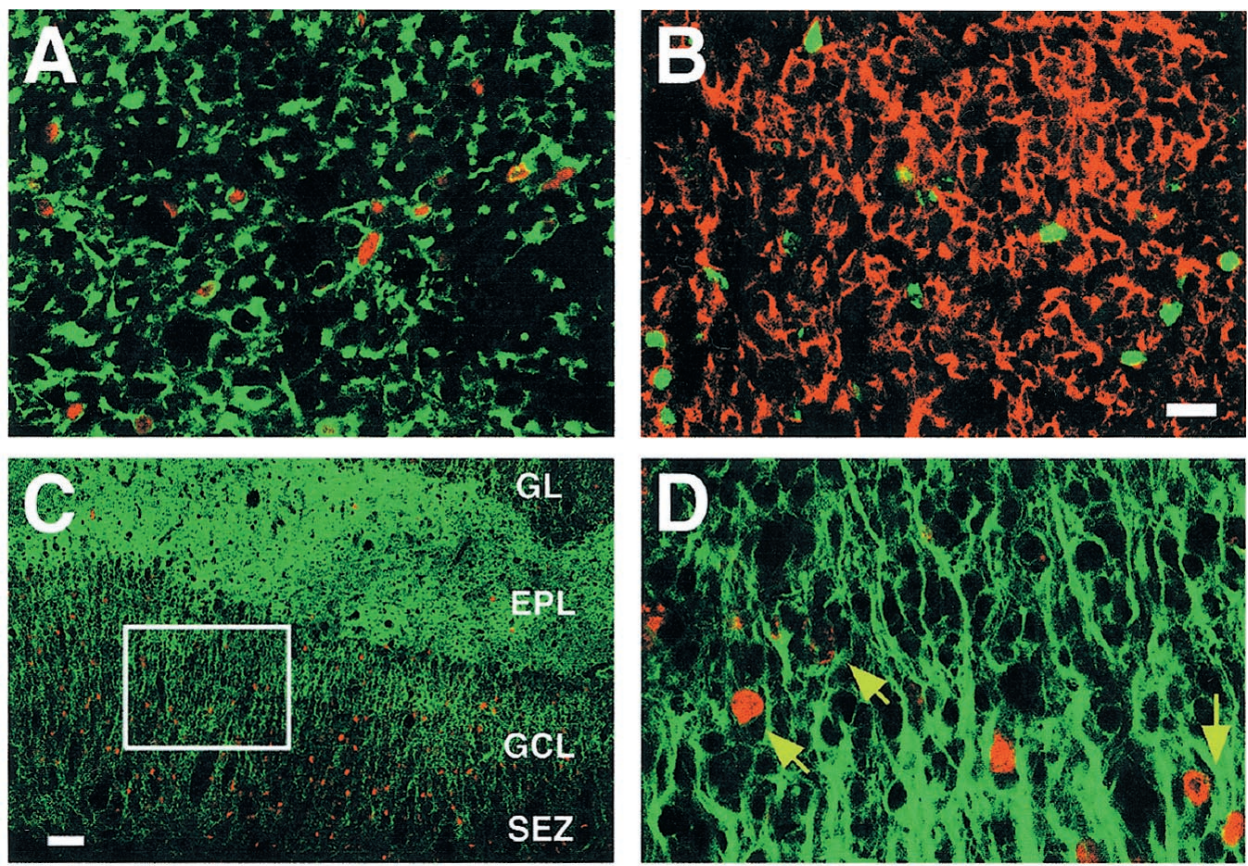

RMS and olfactory bulb induced SE. $A, B$, Confocal images of coronal sections through the RMS immunofluorescently double-labeled for BrdU (red) and neuron-specific $\beta$-tubulin (green in $A$ ) or $\mathrm{BrdU}$ (green) and PSA-NCAM (red in $B$ ) in an adult rat $14 \mathrm{~d}$ after SE ( $7 \mathrm{~d}$ after BrdU injections). Nearly all BrdU-IR cells coexpress these neuronal markers. $C$, Confocal images of a coronal olfactory bulb section immunofluorescently double-labeled for BrdU (red) and neuron-specific $\beta$-tubulin (green) $21 \mathrm{~d}$ after SE. Many BrdU-labeled cells are seen in the olfactory granule cell layer at this time point $(C)$. $D$, A higher magnification view of the boxed area in $C$; yellow arrows point to clusters of doublelabeled cells. $E-J, \mathrm{RV}$ - $\beta$-gal $(E, G, H)$ or $\operatorname{RV-GFP}(F, I, J)$ retroviral reporters were injected stereotactically into the SVZ either $10 \mathrm{~d}$ after SE (RV- $\beta$-gal) or $2 \mathrm{~d}$ before SE (RV-GFP). The presence of reporterlabeled cells in the RMS and olfactory bulb 2 weeks $(E)$ or $11 \mathrm{~d}(F)$ after RV injections confirms that SVZ precursors continue to migrate to the olfactory bulb after SE. $F$, The RV-GFP reporter clearly fills the cells and shows the morphology of the migrating neuroblasts in the RMS (arrow) and more differentiated neurons in the olfactory bulb (arrowhead). Sections are counterstained with nuclear fast red $(E)$ or propidium iodide $(F) . G, H, \mathrm{RV}$ - $\beta$-gal-labeled cells in the olfactory bulb coexpress neuron-specific $\beta$-tubulin (arrows) $24 \mathrm{~d}$ after SE. I, J, RVGFP-labeled cells (green) coexpress the mature neuronal marker NeuN (red; double-labeled cells are yellow) $21 \mathrm{~d}$ after $\mathrm{SE}$ and display the morphology of differentiated olfactory granule $(I)$ or periglomerular $(J)$ neurons. Scale bars: $A, B$ (in $B), 25$ $\mu \mathrm{m} ; C, 75 \mu \mathrm{m} ; E, 150 \mu \mathrm{m} ; F, 100 \mu \mathrm{m} ; D$, $G-J$ (in $J$ ), $10 \mu \mathrm{m}$. SEZ, Subependymal zone; $G C L$, granule cell layer; $E P L$, external plexiform layer; $G L$, glomerular layer.
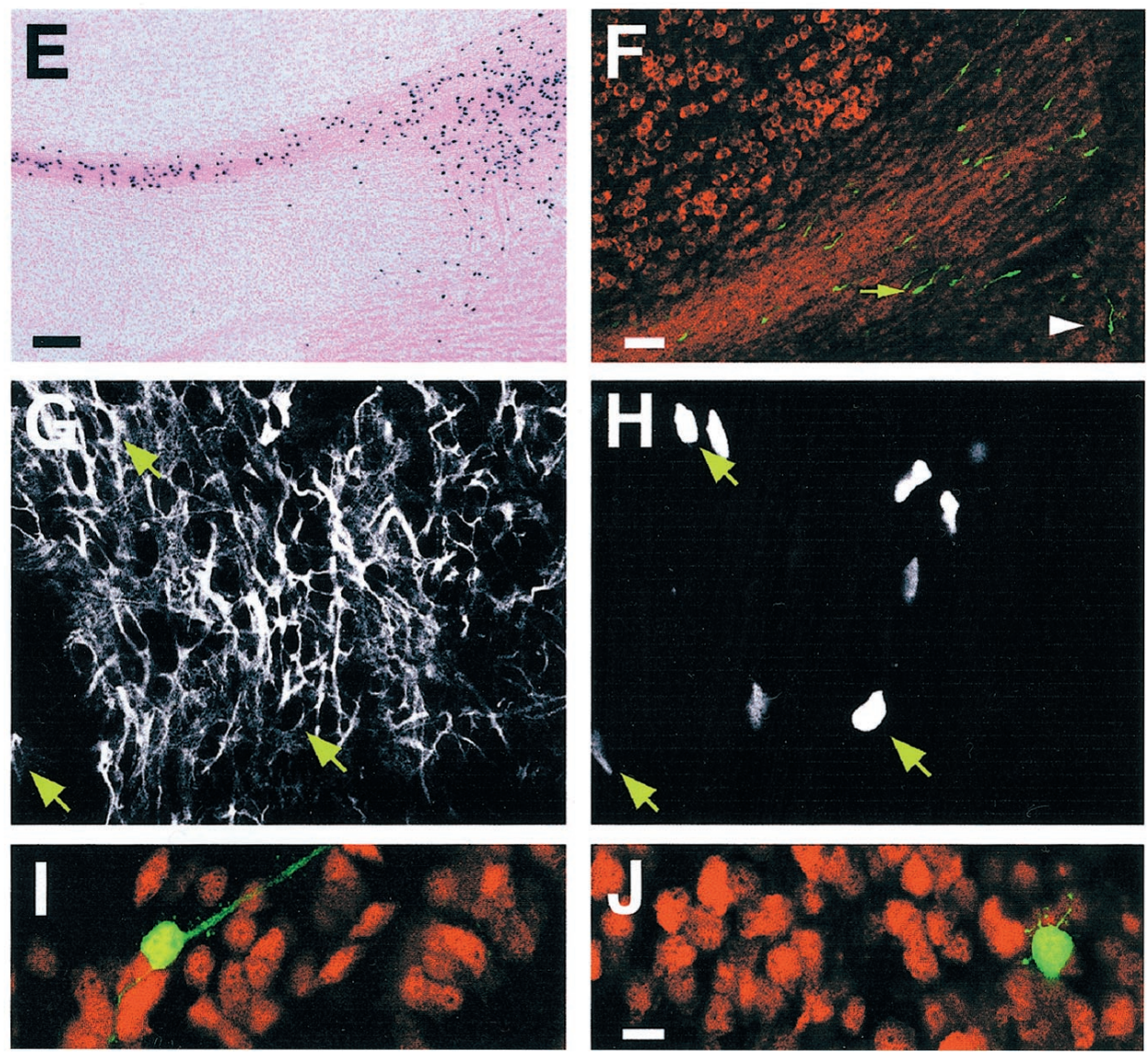

high-titer, replication-deficient, retrovirus carrying nls $\beta$-gal (RV$\beta$-gal) or eGFP (RV-GFP) reporters into the SVZ of adult rats. Like BrdU, retroviral reporters specifically label S-phase cells and integrate into the DNA so that the reporters are expressed faithfully in the precursor progeny. When RV- $\beta$-gal was injected into the SVZ $10 \mathrm{~d}$ after SE and the animals were killed 2 weeks later, labeled cells were found throughout the RMS and olfactory bulb (Fig. $6 E$ ). The RV- $\beta$-gal-immunoreactive cells in the olfactory bulb were identified as neurons by coexpression of neuronspecific $\beta$-tubulin (Fig. $6 G, H$ ). To determine the migration patterns of precursors in the SVZ that were proliferating constitutively before SE, we injected RV-GFP into the SVZ 2 d before pilocarpine treatment. Then $11 \mathrm{~d}$ later GFP-labeled cells with migratory or more differentiated neuroblast morphology 


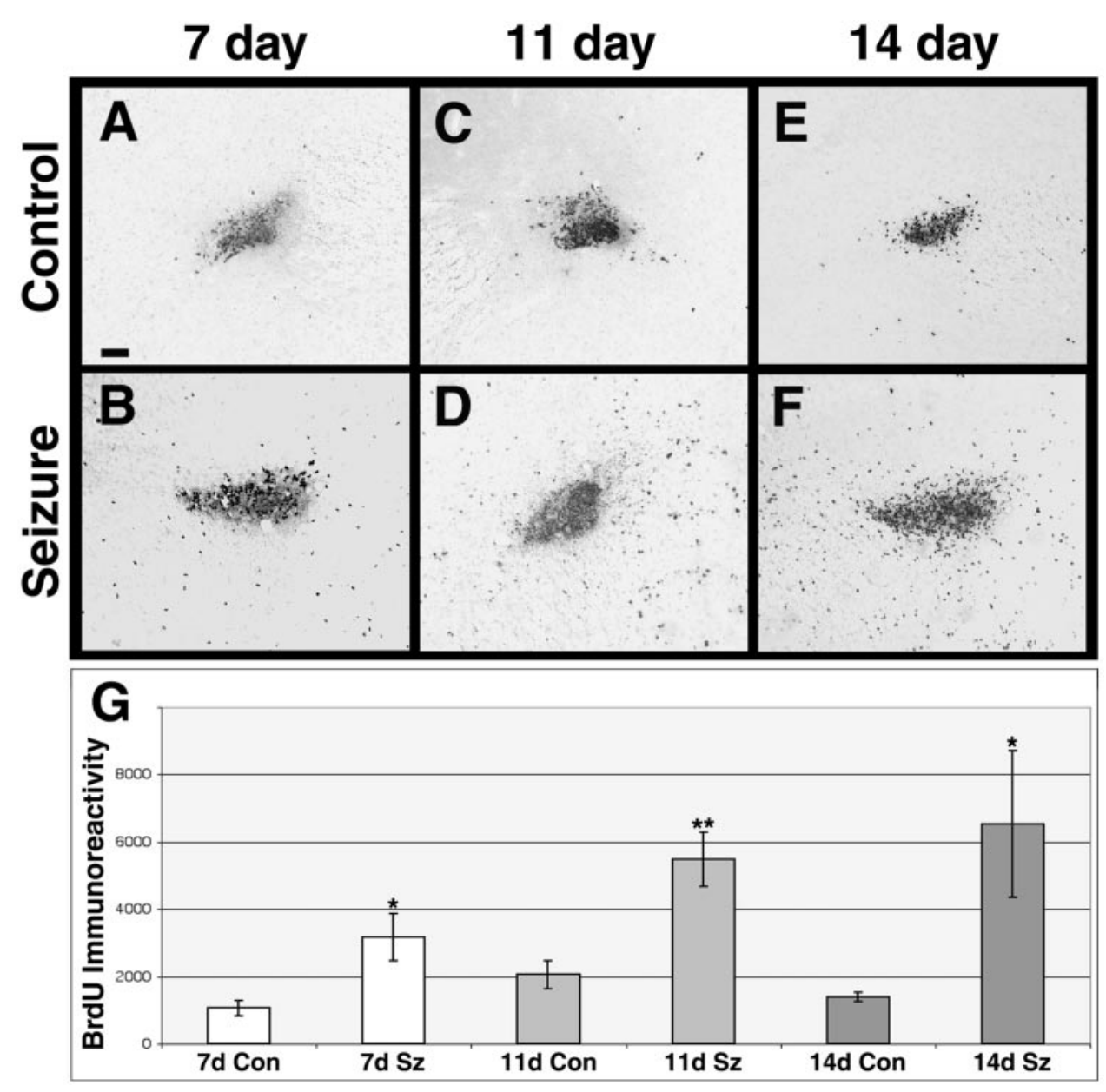

Figure 7. Seizures increase BrdU labeling adjacent to the RMS. $A-F$, BrdU was administered $7 \mathrm{~d}$ after saline $(A, C, E)$ or pilocarpine $(B, D, F)$ treatment, and animals were killed $1 \mathrm{hr}(A, B), 4 \mathrm{~d}(C, D)$, or $7 \mathrm{~d}(E$, $F)$ later. Note that BrdU labeling outside the RMS is increased in the pilocarpine-treated rat compared with control at each time point and that the labeling increases with longer survival durations after BrdU administration in the seizure group. $G$, Quantification of BrdU-immunostained cells adjacent to the RMS (see Materials and Methods) in controls and pilocarpine-treated rats. Error bars represent SEM. * $p<0.05$ seizure versus control; ${ }^{* *} p<0.01$. Scale bar (in $A$ ), $50 \mu \mathrm{m}$. appeared in the RMS and olfactory bulb, respectively (Fig. 6F). At $21 \mathrm{~d}$ after SE the RV-GFP-labeled cells in the olfactory bulb had the appearance of differentiated olfactory neurons and expressed the mature neuronal marker NeuN (Fig. 6I,J). So that retroviral labeling of dividing RMS and olfactory bulb cells by diffusion of retrovirus from the injection site could be excluded, three controls received $\mathrm{RV}$ - $\beta$-gal injections in the rostral SVZ and were killed $3 \mathrm{~d}$ later. In all of these animals the majority of labeled cells was seen in the SVZ and adjacent to the injection track. Rare scattered $\beta$-gal-expressing cells were seen in the proximal RMS, consistent with a short-distance migration of these cells from the SVZ. As expected, however, no labeled cells were found in the distal RMS or olfactory bulb. These results indicate that SE increases the migration of forebrain SVZ neural precursors to the olfactory bulb, where the cells differentiate into neurons.

\section{SE induces immature neurons to migrate ectopically into the forebrain}

At nearly all RMS levels in pilocarpine-treated animals, cells with migrating neuroblast morphology that expressed immature neuronal markers extended out from the borders of the RMS or were located well outside the migratory stream (Fig. 4). Putative newly generated neuroblasts, identified by doublecortin immunostaining, were also found in the striatum of pilocarpine-treated rats (see Fig. 8D). Such "ectopic" cells in the striatum and regions near the RMS were not observed in controls. Moreover, the distribution of migratory profiles adjacent to the RMS corre- sponded to the pattern of increased BrdU labeling in these regions after SE (Fig. 3C-F). These findings suggested that the ectopic cells were newly generated neurons. To test this theory further, we performed double-label immunofluorescence for BrdU and cell type-specific antigens. Newly generated cells that had incorporated BrdU on day 7 after pilocarpine treatment were found 1 week later to be located in regions adjacent to, but well outside of, the RMS. These cells coexpressed the immature neuronal markers CRMP-4, neuron-specific $\beta$-tubulin, or PSANCAM (see Fig. $8 A-C$; data not shown). Many of the cells had the appearance of migrating neuroblasts extending away from the migratory stream toward cortical regions. Cells outside the RMS only rarely showed colocalization of BrdU and astrocyte or endothelial cell markers (data not shown).

To determine the origin of these potentially ectopic newly generated neurons, we administered BrdU $7 \mathrm{~d}$ after pilocarpine or saline treatment and then measured BrdU labeling in areas adjacent to the RMS after different survival durations. We found that BrdU-IR cells outside of the migratory pathway increased in number between 7 and $14 \mathrm{~d}$ after SE (from $1 \mathrm{hr}$ to $7 \mathrm{~d}$ after BrdU injections; Fig. $7 A-F$ ). This increase was significant at each time point for pilocarpine-treated rats when compared with controls (Fig. 7G). These data further suggest that prolonged seizures induce a portion of newly generated neuroblasts to exit the RMS prematurely. However, another potential explanation is that BrdU labeling increases outside of the RMS between 7 and $14 \mathrm{~d}$ after SE because of the continued proliferation of cells that are 

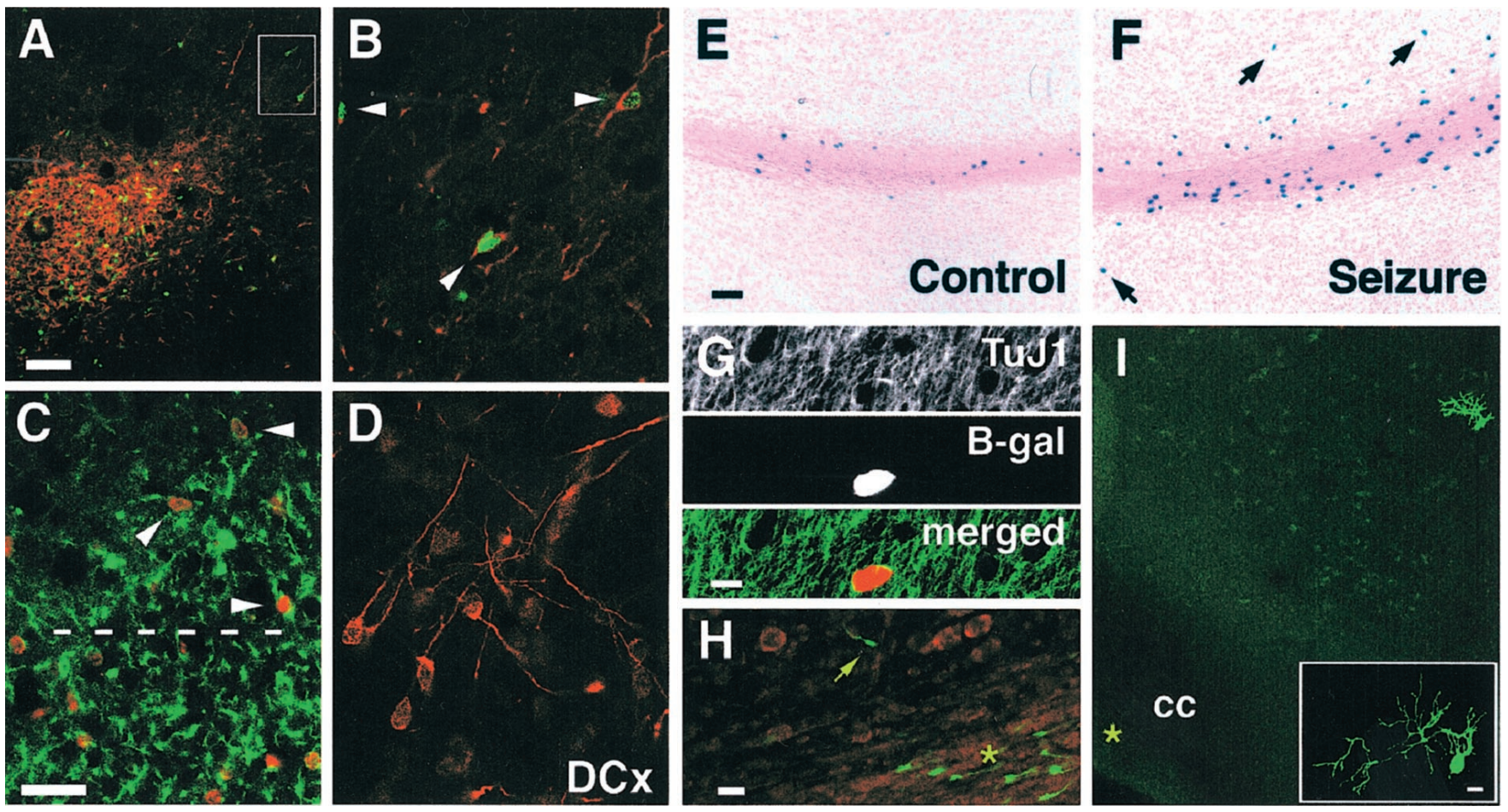

Figure 8. Ectopic migration of neuroblasts from the RMS after SE. $A-C$, BrdU-IR cells ( green in $A$, $B ;$ red in $C$ ) within and outside the RMS $14 \mathrm{~d}$ after SE coexpress CRMP-4 (red in $A, B$ ) or neuron-specific $\beta$-tubulin ( green in $C$ ) and have the morphology of migrating neuroblasts. A higher-magnification view of the boxed region in $A$ is shown in $B$. The dashed line in $C$ represents the dorsal edge of the RMS. Arrowheads point to double-labeled cells outside of the RMS. $D$, Doublecortin $(D C x)$-IR cells in the striatum $14 \mathrm{~d}$ after SE. $E-G, \mathrm{RV}-\beta$-gal injected into the rostral SVZ $10 \mathrm{~d}$ after saline $(E)$ or pilocarpine $(F, G)$ treatment labels cells in the RMS 14 d later. RV- $\beta$-gal-labeled cells in the control remain restricted to the RMS $(E)$. After SE $(F)$ many more labeled cells are present within the RMS, and some cells have migrated outside the RMS (arrows). $G$, RV- $\beta$-gal-labeled cell outside the RMS coexpresses neuron-specific $\beta$-tubulin. $H, I$, RV-GFP was injected into the rostral SVZ $2 \mathrm{~d}$ before SE, and labeled cells were detected $21 \mathrm{~d}(H)$ or $35 \mathrm{~d}$ $(I)$ after seizures. Although most of the RV-GFP-labeled cells were confined to the RMS (asterisk in $H$ ), a labeled cell (arrow in $H$ ) is seen outside the RMS. I, RV-GFP-labeled cell is located in frontal cortex distant from the RMS (asterisk). The inset shows the differentiated neuron-like morphology of the cell. Additional confocal optical sections of the $z$-series show that the process inferior to the cell body has an axonal morphology (data not shown). Scale bars: $A, I$ (in $A$ ), $100 \mu \mathrm{m} ; B-D$ (in $C$ ), $50 \mu \mathrm{m} ; E, F$ (in E), $75 \mu \mathrm{m} ; G, 7.5 \mu \mathrm{m} ; H, 25 \mu \mathrm{m}$; Inset in $I, 10 \mu \mathrm{m}$. $C C$, Corpus callosum.

already in that region, rather than because of the migration of newly generated cells from the SVZ-olfactory bulb pathway. To identify the source of the ectopic neuroblasts more definitively, we examined whether neuronal precursors labeled by stereotactic SVZ retroviral reporter injections migrate from the RMS after $\mathrm{SE}$. When RV- $\beta$-gal was injected into the rostral SVZ of controls, labeled cells in RMS regions 1 week later were confined to the migratory pathway (Fig. $8 E$ ), similar to previous findings in neonatal rats (Luskin, 1993). In pilocarpine-treated rats receiving SVZ RV- $\beta$-gal injections $7 \mathrm{~d}$ after SE, however, increased numbers of labeled cells were present in the RMS after 1 week (Fig. $8 F$ ). Moreover, cells outside of the RMS also were labeled with the reporter, confirming their origin in the SVZ. The neuronal identity of $\beta$-gal expressing cells outside the RMS was indicated by their coexpression of neuron-specific $\beta$-tubulin (Fig. 8G). In similar experiments RV-GFP was injected $2 \mathrm{~d}$ before pilocarpine or saline treatment. Three weeks later the GFP-labeled cells were found both within and outside the RMS after SE (Fig. $8 H$ ) but were restricted to the RMS in controls (data not shown). Of note, rare GFP-labeled cells with apparent neuronal morphology persisted in cortical regions up to $35 \mathrm{~d}$ after SE (Fig. 8I). Such cells were scarce compared with the numbers of cells that appeared to exit the RMS at earlier time points after SE (Fig. 4). These findings indicate that prolonged seizures induce a portion of newly generated SVZ neuroblasts to migrate from the RMS into injured forebrain regions. However, the lack of significant num- bers of newly generated putative neurons in the neocortex after SE suggests that the majority of neuroblasts migrating ectopically into the forebrain fails to survive.

\section{DISCUSSION}

The effects of brain injury on persistent neural precursor cells in the adult rodent forebrain SVZ are poorly understood. We used both endogenous and exogenous markers of dividing cells to show that pilocarpine-induced SE increases proliferating cell numbers in the adult rat rostral SVZ and RMS. Our results also indicate that prolonged seizures expand the neuroblast population in the SVZ-olfactory bulb pathway. The proliferative effect of seizures appears to be highly selective for neuronal precursors, because relatively little change in astrocyte lineage cells arose in these neurogenic regions despite the presence of marked seizureinduced astrocyte proliferation in nearby areas. Moreover, we found that SE increases neuronal precursor migration to the olfactory bulb and induces a portion of RMS neuroblasts to exit the pathway prematurely and migrate aberrantly into other forebrain regions.

The dynamic nature of SVZ-olfactory bulb neurogenesis complicates the analysis of how seizure-induced injury alters this neurogenic pathway. For example, although new cells are produced continually in the rodent forebrain SVZ, these precursors migrate several millimeters or more from the SVZ to the olfactory bulb within days and continue to divide in the RMS while 
migrating (Lois and Alvarez-Buylla, 1994; Lois et al., 1996; Luskin, 1998). SE could expand the SVZ-RMS neuroblast population via a number of mechanisms acting alone or in combination. These include increasing the rate of neuronal precursor generation, enhancing their short-term survival, or accelerating neuroblast migration rostrally from more caudal SVZ locations. The prolonged expansion of proliferating cells and immature neurons throughout the entire length of the RMS (Fig. 3F) suggests an increase in the overall size of the neuroblast population. This is supported further by our finding of increased immunostaining for immature neurons at more caudal (as well as rostral) SVZ levels (Fig. 3). However, further study is needed to determine the relative contribution of increased neurogenesis, enhanced survival, or altered migration after seizure-induced injury. Another potential explanation for the seizure-induced expansion of the proliferating SVZ-RMS neuroblast population is that precursors accumulate from a failure to migrate to the olfactory bulb, as has been seen after bulbectomy or transection lesions of the RMS (Jankovski et al., 1998; Alonso et al., 1999; Kirschenbaum et al., 1999). We tested this possibility by determining the extent of olfactory bulb BrdU labeling after progressively longer survival durations (BrdU pulse-chase) and by using stereotactic SVZ retroviral reporter injections to track precursor migration. These experiments demonstrated that SVZ neuroblasts are not impeded from migrating to the olfactory bulb. Thus, our findings indicate that pilocarpine-induced SE markedly expands the neuroblast population in the SVZ and RMS.

Persistent germinative zones in the adult rodent brain appear to respond to injury in a remarkably similar manner regardless of whether damage is induced by seizures or other acute insults. We found that increased SVZ neurogenesis after SE occurs with a latent period and overall time course that parallel the accelerated neurogenesis in the adult rat dentate gyrus reported in several different epilepsy models (Parent et al., 1997; Gray and Sundstrom, 1998). Cell proliferation and neurogenesis in the adult rodent dentate gyrus also increase after mechanical and ischemic injury (Gould and Tanapat, 1997; Liu et al., 1998). Likewise, rostral SVZ cell proliferation is stimulated by a variety of different forebrain insults, including aspiration or transection lesions (Willis et al., 1976; Szele and Chesselet, 1996; Weinstein et al., 1996), inflammation (Calzà et al., 1998), and chemical demyelination (Nait-Oumesmar et al., 1999). In the latter injury model the progeny of SVZ precursors appeared to differentiate into glial cells, whereas the daughter cell fates and final destinations in the other investigations were not characterized. To our knowledge, the only other report of increased SVZ neurogenesis induced by injury is the recent study by Fallon and colleagues (2000). These authors showed in the adult rat 6-hydroxydopamine model of Parkinson's disease that the combination of dopaminergic neuron lesions in the substantia nigra and transforming growth factor- $\alpha$ inf usion into the ipsilateral striatum increased forebrain SVZ cell proliferation and induced directed neuroblast migration and striatal neurogenesis. Taken together with our findings of seizureinduced increases in SVZ neuroblast numbers, these results suggest that persistent germinative zones in the adult mammalian brain offer a potential source for cell replacement after injury. Moreover, potentially similar cues induced by different types of injury appear to expand the endogenous neural precursor population, including those cells with the potential to form new neurons.

The signals that lead to increased cell proliferation and neurogenesis after seizures or other causes of brain injury are poorly understood. The idea that cell death may be necessary to induce new cell production is supported by studies that have found increased neurogenesis after targeted apoptosis in adult mouse neocortex and adult songbird brain (Magavi et al., 2000; Scharff et al., 2000). This same mechanism also may operate normally in the adult rodent SVZ-olfactory bulb pathway to induce cell replacement (Biebl et al., 2000). Because damage occurs to the main and accessory olfactory bulbs in the pilocarpine epilepsy model (Turski et al., 1983), the expansion of SVZ neuroblasts induced by seizures could be a response to this damage. Our data suggest that the majority of SVZ neural precursors produced after pilocarpine-induced SE remains in the SVZ-olfactory bulb pathway and therefore would be capable of potentially replacing lost neurons. However, it is not yet known whether the olfactory bulb neurons generated in the epileptic brain survive and integrate functionally into existing networks. Direct electrical activation during seizures or more physiological activity, such as long-term potentiation, also has been proposed to accelerate cell proliferation and neurogenesis in the adult rodent brain (Parent et al., 1997; Derrick et al., 2000). Such stimuli have not been dissociated unequivocally from injury, however, given the finding that cell death can occur even during brief seizure-like episodes (Bengzon et al., 1997).

A number of specific local molecular cues or cell-autonomous factors are candidates for mediating seizure-induced increases in proliferating neuroblasts. Seizure activity is known to increase the expression of growth or neurotrophic factors that are mitogenic for adult SVZ stem cells or that can influence their differentiation or survival. These include bFGF (Riva et al., 1992; Humpel et al., 1993; Gall et al., 1994), EGF-like molecules (Opanashuk et al., 1999), IGF-1 (Young and Dragunow, 1995), and BDNF (Ernfors et al., 1991; Isackson et al., 1991; DugichDjordjevic et al., 1992). Seizures also induce a marked astrocyte proliferation (Figs. $3 H, 7 D$ ), and there is evidence that contactmediated interaction with astrocytes can stimulate adult rodent SVZ neural precursor proliferation in vitro (Lim and AlvarezBuylla, 1999). Other molecules involved in intercellular contacts, including specific integrins, ephrins, and Eph receptor tyrosine kinases, also may influence SVZ precursor migration and proliferation (Jacques et al., 1998; Conover et al., 2000). Finally, certain bone morphogenetic protein (BMP) family members appear to act in a cell-autonomous manner to block adult rodent SVZ neurogenesis, whereas neurogenesis is promoted by the BMP antagonist Noggin (Lim et al., 2000). The effects of seizures on these various signaling molecules and their potential role in seizure-induced neurogenesis remain to be determined.

In addition to increasing the numbers of neuronal precursors migrating to the olfactory bulb, our results show that SE also modifies the migration of SVZ neuroblasts. Using stereotactic retroviral reporter injections, BrdU labeling, and immunostaining for immature neuronal markers, we found that neuronal precursors arising from the SVZ exited the SVZ or RMS prematurely and migrated to ectopic locations in the striatum and cortex. Findings of ectopic neuroblasts also have been reported in the adult rat dentate gyrus after pilocarpine-induced SE (Parent et al., 1997; Scharfman et al., 2000). Several recent studies suggest mechanisms by which SE might induce ectopic migration from the SVZ/RMS and also stimulate neuronal precursor migration to the olfactory bulb. Luskin and colleagues found that intraventricular infusion of BDNF in adult rats increased neuronal precursor migration to the olfactory bulb and also caused neuroblasts to appear in ectopic sites such as the striatum, septum, and thalamus 
(Zigova et al., 1998; Pencea et al., 2001). As mentioned above, SE increases the expression of a number of neurotrophic factors, including BDNF (Ernfors et al., 1991; Isackson et al., 1991; Dugich-Djordjevic et al., 1992). Another recent investigation showed that a glial-derived factor increased the migration rate of neuroblasts from the neonatal rat SVZ-olfactory bulb pathway grown as explant cultures (Mason et al., 2001). This finding fits with the known or suspected importance of glia for various types of neuronal migration (Hatten, 1999), including that of adultgenerated olfactory bulb neuronal precursors (Thomas et al., 1996). Interestingly, we found that GFAP immunostaining markedly increased after SE in regions adjacent to the SVZ and RMS (Figs. 2, 4). This suggests that astrocytes proliferate or are activated in areas in which they might exert effects on SVZ-olfactory bulb neuroblast migration, including the potential induction of aberrant migration. A similar finding of ectopic neuroblast migration from the RMS and along a proliferating glial "scar" has been reported after transection lesions of the migratory stream (Alonso et al., 1999), although in that instance neuroblast migration to the olfactory bulb was blocked by the injury. Importantly, the modulation of SVZ neuroblast proliferation and migration by glia could explain how diverse brain insults exert similar effects on these processes. Such a mechanism also would have implications for how endogenous neuronal precursors respond to acute brain injuries and how this response potentially may be manipulated for therapeutic purposes.

The consequences of increased forebrain SVZ neurogenesis and altered neuroblast migration in the epileptic brain are unknown. Recent studies of seizure-induced dentate gyrus neurogenesis provide evidence that the accelerated birth of neurons after injury may have maladaptive consequences. For example, presumptive newly differentiating dentate granule cell precursors in the epileptic hippocampus have been found to participate in aberrant axonal remodeling (Parent et al., 1997), maintain morphological features of immaturity such as basal dendrites (Spigelman et al., 1998; Buckmaster and Dudek, 1999; Ribak et al., 2000), and appear in abnormal locations such as the dentate hilus (Parent et al., 1997; Scharfman et al., 2000; Dashtipour et al., 2001). Hilar ectopic dentate granule-like cells induced by seizures have been shown to exhibit abnormal, pro-epileptogenic burst firing in hippocampal slice preparations (Scharfman et al., 2000). Whether seizure-induced SVZ neuroblast expansion and ectopic migration result in similar abnormalities of network integration and excitability remains speculative. Alternatively, the common thread of increased neurogenesis from adult forebrain neural precursors after various forms of injury implies that the mature brain maintains a potential for self-repair (Lowenstein and Parent, 1999). We found that prolonged seizures induced migration of a subset of neuronal precursors from the normal pathway toward forebrain regions that are not their typical targets. Although this aberrant neuroblast migration could represent a lowlevel reparative phenomenon after injury, very few putative newborn neurons appeared to survive at least 5 weeks after SE. This suggests that the local cues necessary for their appropriate differentiation and survival may not be present, even after injury. This idea is supported by previous work indicating that only specific forms of injury allow transplanted or endogenous neuronal precursors to survive and integrate into the adult rodent neocortex (Snyder et al., 1997; Magavi et al., 2000). Further study of seizure-induced SVZ neurogenesis is necessary to determine whether new neurons generated after injury survive, integrate, and replace lost cells in the mature forebrain. Knowledge of the mechanisms that regulate endogenous neural precursor cells in normal and disease states may lead to strategies for their use in treating brain injury or degeneration.

\section{REFERENCES}

Alonso G, Prieto M, Chauvet N (1999) Tangential migration of young neurons arising from the subventricular zone of adult rats is impaired by surgical lesions passing through their natural migratory pathway. J Comp Neurol 405:508-528.

Altman J (1969) Autoradiographic and histological studies of postnatal neurogenesis. IV. Cell proliferation and migration in the anterior forebrain, with special reference to persisting neurogenesis in the olfactory bulb. J Comp Neurol 137:433-458.

Altman J, Das GD (1965) Autoradiographic and histological evidence of postnatal hippocampal neurogenesis in rats. J Comp Neurol 124: 319-335.

Bengzon J, Kokaia Z, Elmer E, Nanobashvili A, Kokaia M, Lindvall O (1997) Apoptosis and proliferation of dentate gyrus neurons after single and intermittent limbic seizures. Proc Natl Acad Sci USA 94:10432-10437.

Ben-Hur T, Rogister B, Murray K, Rougon G, Dubois-Dalcq M (1998) Growth and fate of PSA-NCAM+ precursors of the postnatal brain. J Neurosci 18:5777-5788.

Biebl M, Cooper CM, Winkler J, Kuhn HG (2000) Analysis of neurogenesis and programmed cell death reveals a self-renewing capacity in the adult rat brain. Neurosci Lett 291:17-20.

Bonfanti L, Theodosis DT (1994) Expression of polysialylated neural cell adhesion molecule by proliferating cells in the subependymal layer of the adult rat, in its rostral extension and in the olfactory bulb. Neuroscience 62:291-305.

Buckmaster PS, Dudek FE (1999) In vivo intracellular analysis of granule cell axon reorganization in epileptic rats. J Neurophysiol 81: $712-721$.

Calzà L, Giardino L, Pozza M, Bettelli C, Micera A, Aloe L (1998) Proliferation and phenotype regulation in the subventricular zone during experimental allergic encephalomyelitis: in vivo evidence of a role for nerve growth factor. Proc Natl Acad Sci USA 95:3209-3214.

Cameron HA, Woolley CS, McEwen BS, Gould E (1993) Differentiation of newly born neurons and glia in the dentate gyrus of the adult rat. Neuroscience 56:337-344.

Cepko C, Ryder EF, Austin CP, Walsh C, Fekete DM (1995) Lineage analysis using retrovirus vectors. Methods Enzymol 254:387-419.

Conover JC, Doetsch F, García-Verdugo JM, Gale NW, Yancopoulos GD, Alvarez-Buylla A (2000) Disruption of Eph/ephrin signaling affects migration and proliferation in the adult subventricular zone. Nat Neurosci 3:1091-1097.

Craig CG, Tropepe V, Morshead CM, Reynolds BA, Weiss S, van der Kooy D (1996) In vivo growth factor expansion of endogenous subependymal neural precursor cell populations in the adult mouse brain. J Neurosci 16:2649-2658.

Cremer H, Lange R, Christoph A, Plomann M, Vopper G, Roes J, Brown R, Baldwin S, Kraemer P, Scheff S (1994) Inactivation of the N-CAM gene in mice results in size reduction of the olfactory bulb and deficits in spatial learning. Nature 367:455-459.

Dashtipour K, Tran PH, Okazaki MM, Nadler JV, Ribak CE (2001) Ultrastructural features and synaptic connections of hilar ectopic granule cells in the rat dentate gyrus are different from those of granule cells in the granule cell layer. Brain Res 890:261-271.

Derrick BE, York AD, Martinez Jr JL (2000) Increased granule cell neurogenesis in the adult dentate gyrus following mossy fiber stimulation sufficient to induce long-term potentiation. Brain Res 857:300-307.

Doetsch F, Alvarez-Buylla A (1996) Network of tangential pathways for neuronal migration in adult mammalian brain. Proc Natl Acad Sci USA 93:14895-14900.

Dugich-Djordjevic MM, Tocco G, Willoughby DA, Najm I, Pasinetti G, Thompson RF, Baudry M, Lapchak PA, Hefti F (1992) BDNF mRNA expression in the developing rat brain following kainic acid-induced seizure activity. Neuron 8:1127-1138.

Eriksson PS, Perfilieva E, Bjork-Eriksson T, Alborn A, Nordborg C, Peterson DA, Gage FH (1998) Neurogenesis in the adult human hippocampus. Nat Med 4:1313-1317.

Ernfors P, Bengzon J, Kokaia Z, Persson H, Lindvall O (1991) Increased levels of messenger RNAs for neurotrophic factors in the brain during epileptogenesis. Neuron 7:165-176.

Fallon J, Reid S, Kinyamu R, Opole I, Opole R, Baratta J, Korc M, Endo TL, Duong A, Nguyen G, Karkehabadhi M, Twardzik D, Patel S, Loughlin S (2000) In vivo induction of massive proliferation, directed migration, and differentiation of neural cells in the adult mammalian brain. Proc Natl Acad Sci USA 97:14686-14691.

Gall CM, Berschauer R, Isackson PJ (1994) Seizures increase basic fibroblast growth factor mRNA in adult rat forebrain neurons and glia. Mol Brain Res 21:190-205.

Gates MA, Thomas LB, Howard EM, Laywell ED, Sajin B, Faissner A, 
Gotz B, Silver J, Steindler DA (1995) Cell and molecular analysis of the developing and adult mouse subventricular zone of the cerebral hemispheres. J Comp Neurol 361:249-266.

Gleeson JG, Lin PT, Flanagan LA, Walsh CA (1999) Doublecortin is a microtubule-associated protein and is expressed widely by migrating neurons. Neuron 23:257-271.

Gould E, Tanapat P (1997) Lesion-induced proliferation of neuronal progenitors in the dentate gyrus of the adult rat. Neuroscience 80:427-436.

Gould E, Tanapat P, McEwen BS, Flügge G, Fuchs E (1998) Proliferation of granule cell precursors in the dentate gyrus of adult monkeys is diminished by stress. Proc Natl Acad Sci USA 95:3168-3171.

Gray WP, Sundstrom LE (1998) Kainic acid increases the proliferation of granule cell progenitors in the dentate gyrus of the adult rat. Brain Res 790:52-59.

Gritti A, Parati EA, Cova L, Frolichsthal P, Galli R, Wanke E, Faravelli L, Morassutti DJ, Roisen F, Nickel DD, Vescovi AL (1996) Multipotential stem cells from the adult mouse brain proliferate and self-renew in response to basic fibroblast growth factor. J Neurosci 16:1091-1100.

Hatten ME (1999) Central nervous system neuronal migration. Annu Rev Neurosci 22:511-539.

Hinds JW (1968) Autoradiographic study of histogenesis in the mouse olfactory bulb. J Comp Neurol 134:287-304.

Holmin S, Almqvist P, Lendahl U, Mathiesen T (1997) Adult nestinexpressing subependymal cells differentiate to astrocytes in response to brain injury. Eur J Neurosci 9:65-75.

$\mathrm{Hu} \mathrm{H}$ (1999) Chemorepulsion of neuronal migration by Slit2 in the developing mammalian forebrain. Neuron 23:703-711.

Humpel C, Lippoldt A, Chadi G, Ganten D, Olson L, Fuxe K (1993) Fast and widespread increase of basic fibroblast growth factor messenger RNA and protein in the forebrain after kainate-induced seizures. Neuroscience 57:913-922.

Isackson PJ, Huntsman MM, Murray KD, Gall C (1991) BDNF mRNA expression is increased in adult rat forebrain after limbic seizures: temporal patterns of induction distinct from NGF. Neuron 6:937-948.

Jacques TS, Relvas JB, Nishimura S, Pytela R, Edwards GM, Streuli CH, ffrench-Constant C (1998) Neural precursor cell chain migration and division are regulated through different $\beta 1$ integrins. Development $125: 3167-3177$

Jankovski A, Garcia C, Soriano E, Sotelo C (1998) Proliferation, migration, and differentiation of neuronal progenitor cells in the adult mouse subventricular zone surgically separated from its olfactory bulb. Eur J Neurosci 10:3853-3868.

Kaplan MS, Hinds JW (1977) Neurogenesis in adult rat: electron microscopic analysis of light radioautographs. Science 197:1092-1094.

Kirschenbaum B, Goldman S (1995) BDNF promotes the survival of neurons arising from the adult rat forebrain subventricular zone. Proc Natl Acad Sci USA 92:210-214.

Kirschenbaum B, Doetsch F, Lois C, Alvarez-Buylla A (1999) Adult subventricular zone neuronal precursors continue to proliferate and migrate in the absence of the olfactory bulb. J Neurosci 19:2171-2180.

Kishi K (1987) Golgi studies on the development of granule cells of the rat olfactory bulb with reference to migration in the subependymal layer. J Comp Neurol 258:112-124.

Kornack DR, Rakic P (1999) Continuation of neurogenesis in the hippocampus of the adult macaque monkey. Proc Natl Acad Sci USA 96:5768-5773

Kuhn HG, Dickinson-Anson H, Gage FH (1996) Neurogenesis in the dentate gyrus of the adult rat: age-related decrease of neuronal progenitor proliferation. J Neurosci 16:2027-2033.

Kuhn HG, Winkler J, Kempermann G, Thal LJ, Gage FH (1997) Epidermal growth factor and fibroblast growth factor-2 have different effects on neural progenitors in the adult rat brain. $J$ Neurosci 17:5820-5829

Lim DA, Alvarez-Buylla A (1999) Interaction between astrocytes and adult subventricular zone precursors stimulates neurogenesis. Proc Natl Acad Sci USA 96:7526-7531.

Lim DA, Tramontin AD, Trevejo JM, Herrera DG, García-Verdugo M, Alvarez-Buylla A (2000) Noggin antagonizes BMP signaling to create a niche for adult neurogenesis. Neuron 28:713-726.

Liu J, Solway K, Messing RO, Sharp FR (1998) Increased neurogenesis in the dentate gyrus after transient global ischemia in gerbils. J Neurosci 18:7768-7778.

Lois C, Alvarez-Buylla A (1993) Proliferating subventricular zone cells in the adult mammalian forebrain can differentiate into neurons and glia. Proc Natl Acad Sci USA 90:2074-2077.

Lois C, Alvarez-Buylla A (1994) Long-distance neuronal migration in the adult mammalian brain. Science 264:1145-1148.

Lois C, García-Verdugo JM, Alvarez-Buylla A (1996) Chain migration of neuronal precursors. Science 271:978-981.

Lowenstein DH, Parent JM (1999) Brain, heal thyself. Science 283: $1126-1127$

Luskin M (1993) Restricted proliferation and migration of postnatally generated neurons derived from the forebrain subventricular zone. Neuron 11:173-189.
Luskin MB (1998) Neuroblasts of the postnatal mammalian forebrain: their phenotype and fate. J Neurobiol 36:221-233.

Magavi SS, Leavitt BR, Macklis JD (2000) Induction of neurogenesis in the neocortex of adult mice. Nature 405:951-955.

Mason HA, Ito S, Corfas G (2001) Extracellular signals that regulate the tangential migration of olfactory bulb neuronal precursors: inducers, inhibitors, and repellents. J Neurosci 21:7654-7663.

Miller MW, Nowakowski RS (1988) Use of bromodeoxyuridineimmunohistochemistry to examine the proliferation, migration, and time of origin of cells in the central nervous system. Brain Res 457:44-52.

Nacher J, Rosell DR, McEwen BS (2000) Widespread expression of collapsin response-mediated protein 4 in the telencephalon and other areas of the adult rat central nervous system. J Comp Neurol 424:628-639.

Nait-Oumesmar B, Decker L, Lachapelle F, Avellana-Adalid V, Bachelin C, Van Evercooren AB (1999) Progenitor cells of the adult mouse subventricular zone proliferate, migrate, and differentiate into oligodendrocytes after demyelination. Eur J Neurosci 11:4357-4366.

Okano HJ, Pfaff DW, Gibbs RB (1993) RB and cdc2 expression in brain: correlations with ${ }^{3} \mathrm{H}$-thymidine incorporation and neurogenesis. J Neurosci 13:2930-2938.

O'Leary DD (1993) Adding neurons to the adult mammalian brain. Proc Natl Acad Sci USA 90:2101-2102.

Ono K, Tomasiewicz H, Magnuson T, Rutishauser U (1994) N-CAM mutation inhibits tangential neuronal migration and is phenocopied by enzymatic removal of polysialic acid. Neuron 13:595-609.

Opanashuk LA, Mark RJ, Porter J, Damm D, Mattson MP, Seroogy KB (1999) Heparin-binding epidermal growth factor-like growth factor in hippocampus: modulation of expression by seizures and anti-excitotoxic action. J Neurosci 19:133-146.

Ory DS, Neugeboren BA, Mulligan RC (1996) A stable human-derived packaging cell line for production of high titer retrovirus/vesicular stomatitis virus $G$ pseudotypes. Proc Natl Acad Sci USA 93:11400-11406.

Parent JM, Yu TW, Leibowitz RT, Geschwind DH, Sloviter RS, Lowenstein DH (1997) Dentate granule cell neurogenesis is increased by seizures and contributes to aberrant network reorganization in the adult rat hippocampus. J Neurosci 17:3727-3738.

Parent JM, Tada E, Fike JR, Lowenstein DH (1999) Inhibition of dentate granule cell neurogenesis with brain irradiation does not prevent seizure-induced mossy fiber synaptic reorganization in the rat. J Neurosci $19: 4508-4519$

Paxinos G, Watson C (1998) The rat brain in stereotaxic coordinates. San Diego: Academic

Pencea V, Bingaman KD, Wiegand SJ, Luskin MB (2001) Infusion of brain-derived neurotrophic factor into the lateral ventricle of the adult rat leads to new neurons in the parenchyma of the striatum, septum, thalamus, and hypothalamus. J Neurosci 21:6706-6717.

Peretto P, Merighi A, Fasolo A, Bonfanti L (1997) Glial tubes in the rostral migratory stream of the adult rat. Brain Res Bull 42:9-21.

Peretto P, Merighi A, Fasolo A, Bonfanti L (1999) The subependymal layer in rodents: a site of structural plasticity and cell migration in the adult mammalian brain. Brain Res Bull 49:221-243.

Reynolds BA, Weiss S (1992) Generation of neurons and astrocytes from isolated cells of the mammalian central nervous system. Science 255:1707-1710.

Ribak CE, Tran PH, Spigelman I, Okazaki MM, Nadler JV (2000) Status epilepticus-induced hilar basal dendrites on rodent granule cells contribute to recurrent excitatory circuitry. J Comp Neurol 428:240-253.

Richards LJ, Kilpatrick TJ, Bartlett PF (1992) De novo generation of neuronal cells from the adult mouse brain. Proc Natl Acad Sci USA 89:8591-8595.

Riva MA, Gale K, Mocchetti I (1992) Basic fibroblast growth factor mRNA increases in specific brain regions following convulsive seizures. Mol Brain Res 15:311-318.

Scharff C, Kirn JR, Grossman M, Macklis JD, Nottebohm F (2000) Targeted neuronal death affects neuronal replacement and vocal behavior in adult songbirds. Neuron 25:481-492.

Scharfman HE, Goodman JH, Sollas AL (2000) Granule-like neurons at the hilar/CA3 border after status epilepticus and their synchrony with area CA3 pyramidal cells: functional implications of seizure-induced neurogenesis. J Neurosci 20:6144-6158.

Snyder EY, Yoon C, Flax JD, Macklis JD (1997) Multipotent neural precursors can differentiate toward replacement of neurons undergoing targeted apoptotic degeneration in adult mouse neocortex. Proc Nat Acad Sci USA 94:11663-11668.

Spigelman I, Yan XX, Obenaus A, Lee EY, Wasterlain CG, Ribak CE (1998) Dentate granule cells form novel basal dendrites in a rat model of temporal lobe epilepsy. Neuroscience 86:109-120.

Szele FG, Chesselet M (1996) Cortical lesions induce an increase in cell number and PSA-NCAM expression in the subventricular zone of adult rats. J Comp Neurol 368:439-454.

Theodosis DT, Bonhomme R, Vitiello S, Rougon G, Poulain DA (1999) Cell surface expression of polysialic acid on NCAM is a prerequisite 
for activity-dependent morphological neuronal and glial plasticity. J Neurosci 19:10228-10236.

Thomas LB, Gates MA, Steindler DA (1996) Young neurons from the adult subependymal zone proliferate and migrate along an astrocyte, extracellular matrix-rich pathway. Glia 17:1-14.

Tomasiewicz H, Ono K, Yee D, Thompson C, Goridis C, Rutishauser U, Magnuson T (1993) Genetic deletion of a neural cell adhesion molecule variant (N-CAM) produces distinct defects in the central nervous system. Neuron 11:1163-1174.

Turski WA, Cavalheiro EA, Schwarz M, Czuczwar SJ, Kleinrok Z, Turski L (1983) Limbic seizures produced by pilocarpine in rats: behavioural, electroencephalographic, and neuropathological study. Behav Brain Res 9:315-335.

Wagner JP, Black IB, DiCicco-Bloom E (1999) Stimulation of neonatal and adult brain neurogenesis by subcutaneous injection of basic fibroblast growth factor. J Neurosci 19:6006-6016.
Weinstein DE, Burrola P, Kilpatrick TJ (1996) Increased proliferation of precursor cells in the adult rat brain after targeted lesioning. Brain Res 743:11-16.

Willis P, Berry M, Riches AC (1976) Effects of trauma on cell production in the subependymal layer of the rat neocortex. Neuropathol Appl Neurobiol 2:377-388.

Wu W, Wong K, Chen J, Jiang Z, Dupuis S, Wu JY, Rao Y (1999) Directional guidance of neuronal migration in the olfactory system by the protein Slit. Nature 400:331-336.

Young D, Dragunow M (1995) Neuronal injury following electrically induced status epilepticus with and without adenosine receptor antagonism. Exp Neurol 133:125-137.

Zigova T, Pencea V, Wiegand SJ, Luskin MB (1998) Intraventricular administration of BDNF increases the number of newly generated neurons in the adult olfactory bulb. Mol Cell Neurosci 11:234-245. 